تأثير التدريب المتزامن على بعض المتغيرات البدنية الخاصة

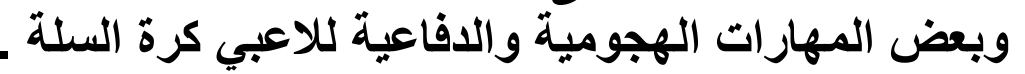

\author{
د. ـ محمد عبد العزيزالجمال

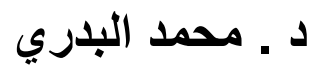

DOI : 10.21608/ijssaa.2020.43288.1311

1/1 المقدمة ومشكلة البحث:

إن الوصول باللاعب إلى البطولة وتحقيق الأرقام والمستوى المهاري العالي في مختلف الأنشطة الرياضية بصفة عامة وكرة السلة بصفة خاصة يرتبط بسلسلة متصلة ومتكاملة من الإجراءات المبنية على أسس علمية لتدريب اللاعب للوصول إلى مستوى البطولة في نوع النشاط الرياضي الممارس، ولا يمكن أن يتحقق ذلك إلا إذا توافرت لدى اللاعب متطلبات هذا النشاط والتي تسهم في الوصول إلى المستويات العالية والتي منها الكفاءة البدنية.

ويشــير ريســـان خريبط وأبو العلا عبد الفتاح (2016م) إلى أن معظم الرياضـــات تتطلب الوصـول إلى قمة الأداء الرياضـى بإسـتخدام صـفتين بدنيتين على الأقل، وتلعب العلاقة بين كل من

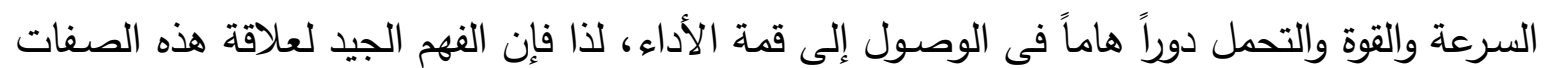
ببعضهها البعض يسـاعد المدرب لتتمية تلك الصـفات وفقاً لمتطلبات النشـاط التخصصس، مثل ارتباط القوة بالتحمل والذى ينتج عنه تحمل القوة أو ارتباط السـرعة بالتحمل والذى ينتج عنه تحمل السـرعة.

Nieman, D. Bشيــير جي بروكس وآخرون . Brooks, G. A., et.al (2000م) ودي نيمسان (2003م) أن مبدأ التدريب يعتمد على طبيعة تكيف الخلايا والأنســـة مع التدريب، ويرجع ذلك إلى ممارسة نوع محدد من التدريب، ووفق هذا المبدأ فإن دمج نوعين من التدريب (تدريب المقاومة وتدريب التحمل) يعطينا نتيجة مختلفة عن تلك التى سنحصل عليها عند ممارسة كل نوع بمفرده. $(85: 26)(328: 13)$

ويشير جون ماكارثي وآخرون .McCARTHY, J. P, et.al (2002م) إلى وجود عملية تحول بين تدريب المقاومة وتدريب التحمل، حيث أن القوة الكلية الناتجة من دمج التدربيين تضـــاعفت عند تزامن التدريب، والدراسـات التى نشرت عن توظيف أنواع مختلفة دن تدريب المقاومة منفرداً وتدريب المقاومة وتدريب التحمل معاً يدعم تلك النتائج. (18: 517) ويضـيف روبرت وود وآخرون .Wood, R. H, et.al. (2001م) أن الطرق التى نشـرت في تلك الدراسـات مثل التدريب النموذجى للمقاومة والتدريب النموذجى للتحمل يتزامن مع فترات التدريب وحجم التدريب، وحالة المتدربين قبل التدريب، وجنس المتدرب وأنماط الأداء والاختبارات الفســـيولوجية 
المســخذمة فى القياس للمعايير المسـتقلة تختلف فى أبعاد هامة، بالإضــافة إلى أنه في العديد من

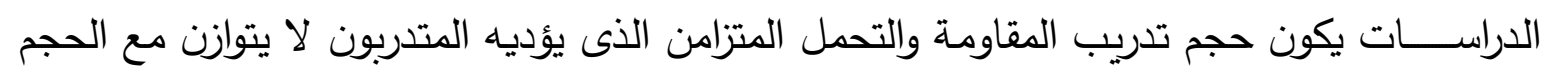

المناظر له الذى يؤديه المتدربون بدون تزامن لتدريب الدقاومة والتحمل. (39: 1756)

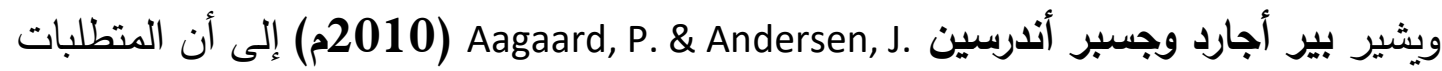

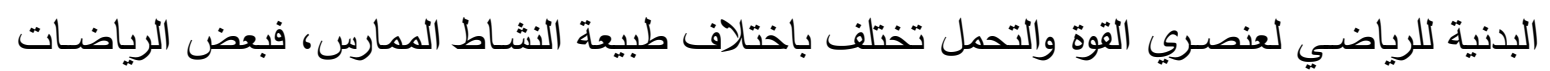

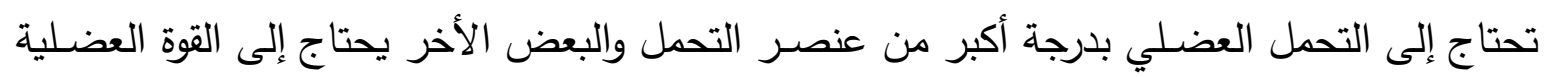

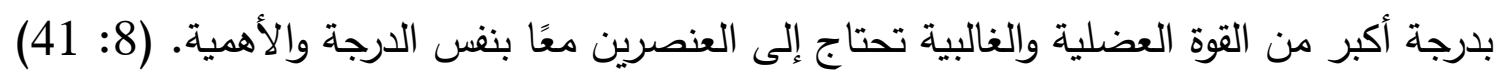

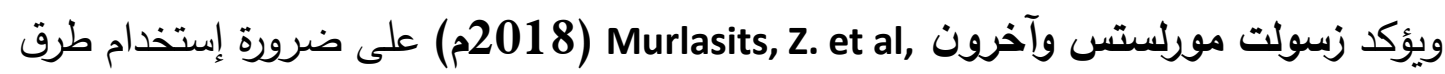

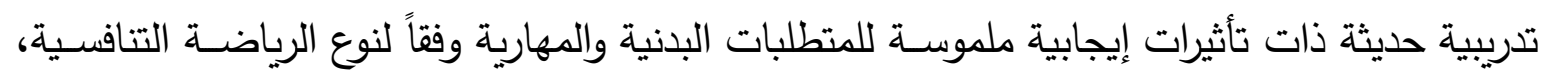
ويعتبر أحد الطرق التدريبية الحديثة اســـتخدام التدريب المتزامن والذي أثبت نتائج فعالة من خلال

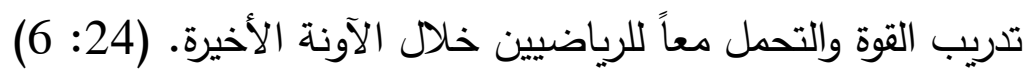

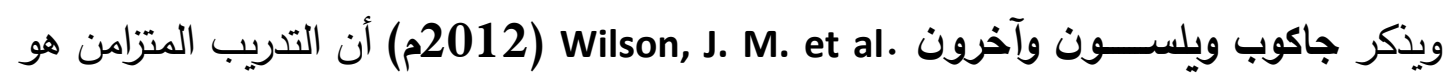

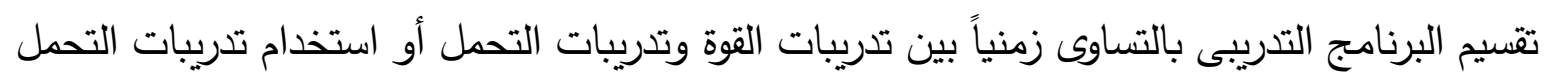

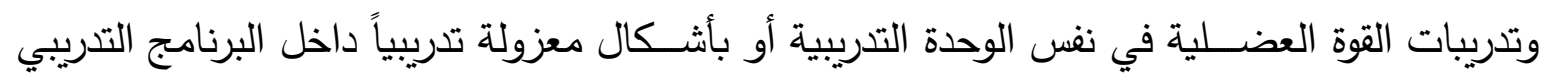
(وحدة تدريبية لتدريبات المقاومة يتبعها وحدة تدريبية لتدريبات التحمل).

ويعد تحمل القوة أثناء الأداء المهاري المتكرر للاعبي كرة السلة من المتطلبات البدنية الأساسية

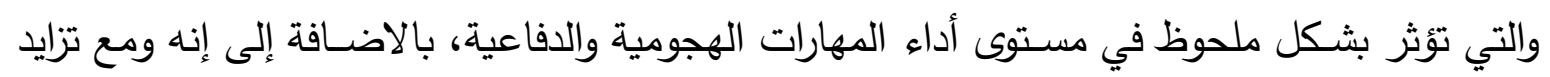

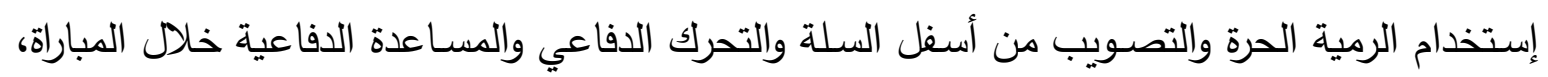

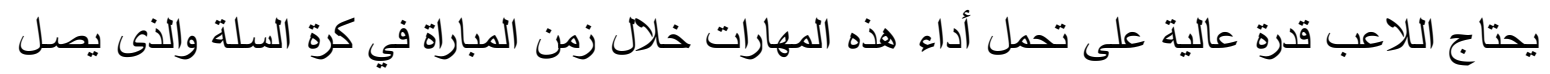

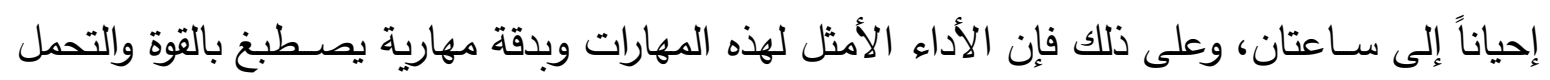

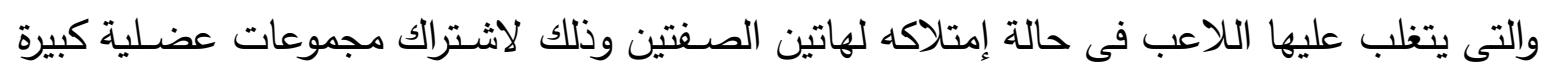
ومحددة خلال هذا الأداء ولفترة طويلة لتحقيق الهدف المطلوب، وهذا يوضح أهمية أهية تتمية صفة التحمل مع القوة فى توقيت متزامن للاعبى كرة السلة.

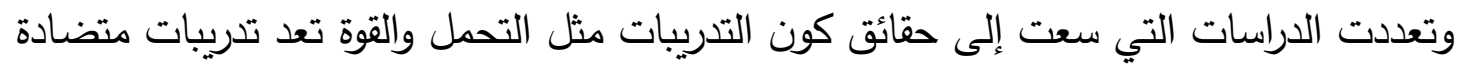
لا يمكن إستخدامها سوياً للاعبين فى وحدة تدريبية واحدة، وعلى النقيض فإن التطور المستمر والمتزايد

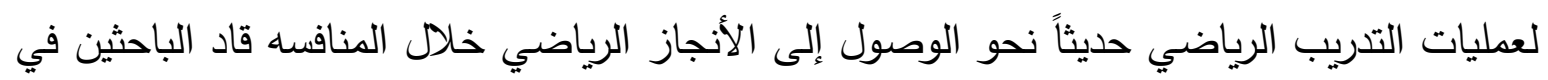

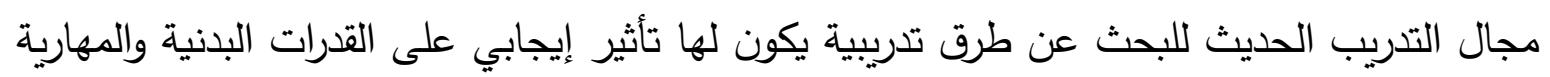

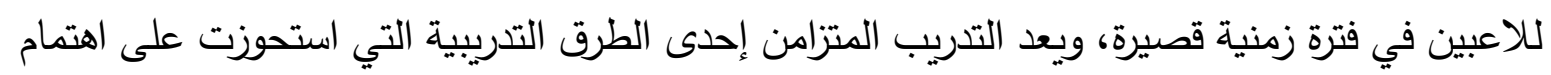

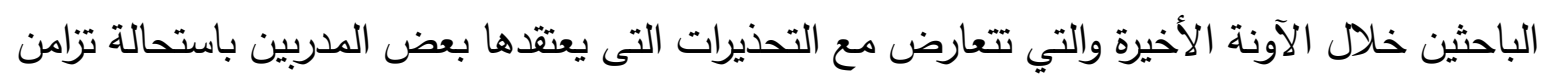


تدريب القوة والتحمل في آن واحد داخل نفس الوحدة التدريبية، مثل دراسة زسولت مورلستس وآخرون Robineau, J. et al, Murlasits, Z. et al,

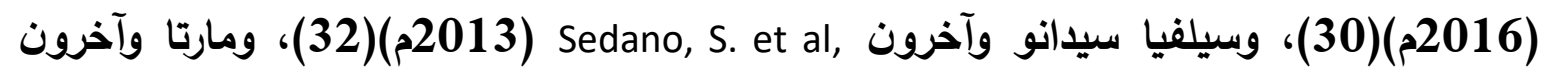
Balabinis, C. P et al. Marta, C. et al,

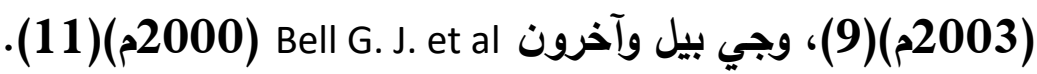
وتعتبر كرة السـلة إحدى الرياضـات الجماعية التى تتطلب قدر عالي من القوة لتتفيذ المتطلبات

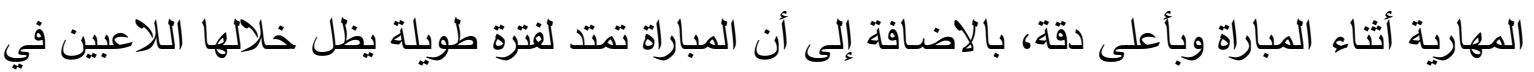

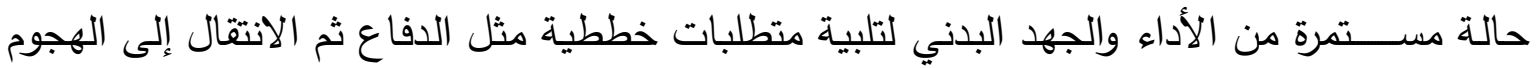

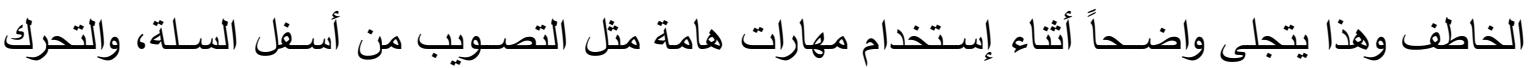

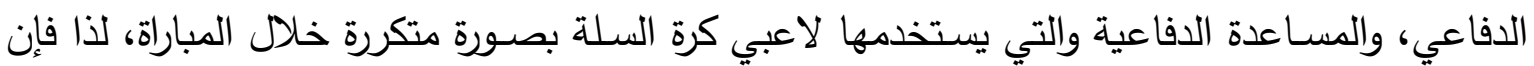

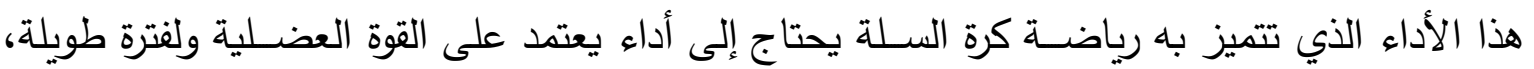

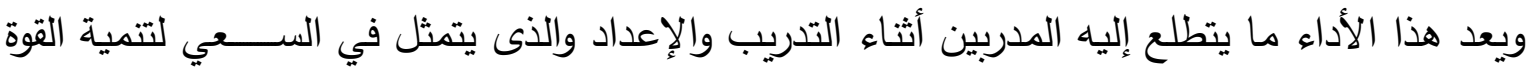

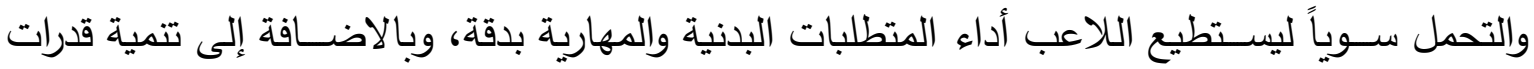

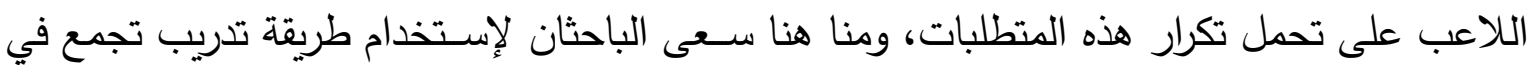

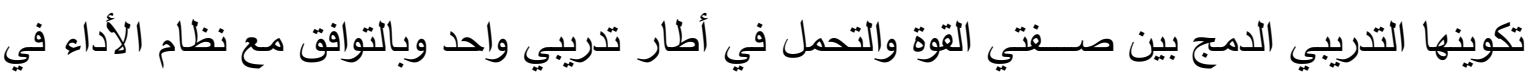
رياضة كرة السلة.

لذا تكمن أهمية البحث في استخدام التدريب المتزامن داخل الواحدات التدريبية للاعبي كرة السلة،

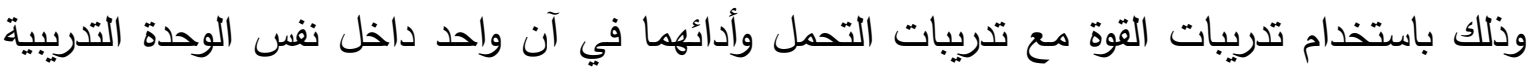

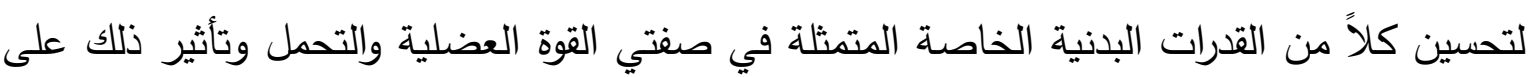
تحسين الأداء الههاري الهجومي والدفاعي وبما يحقق منطلبات الأداء في المباريات.

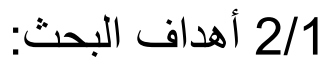
يهدف البحث إلى تصميم برنامج للتدربب المتزامن وذلك للتعرف على:

1/2/1 تأثير البرنامج المتزامن على بعض المتغيرات البدنية الخاصة قيد البحث للاعبي كرة السلة (المجموعة التجريبية).

2/2/1 تأثير البرنامج المتزامن على بعض المهارات الهجومية والدفاعية قيد البحث للاعبي كرة السلة (المجموعة التجريبية).

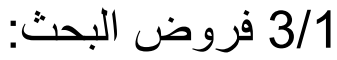
1/3/1 توجد فروق دالة إحصائياً بين القياس القبلي والبعدي للمتغيرات البدنية الخاصة للمجموعة التجريبية ولصالح القياس البعدي. 
2/3/1 توجد فروق دالة إحصائياً بين القياس القبلي والبعدي للمتغيرات المهارات الهجومية والدفاعية للمجموعة التجريبية ولصالح القياس البعدي.

3/3/1 توجد فروق دالة إحصائياً بين القياسين البعديين للمتغيرات البدنية الخاصة وبعض البعائ المهارات الهجومية والدفاعية للمجموعتين التجريبية والضابطة ولصالح المجموعة التجريبية.

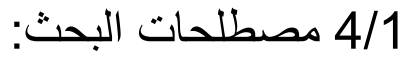
1/4/1 التندريب المتزامن Concurrent Training هو فكرة الجمع بين تدريب التحمل وتدريب القوة العضلية جنباً إلى جنب في برنامج تدريبي واحد.

0/2 الدر اسات السابقة و المرتبطة: 1/2/2 قام زبولت مورلستس وآخرون Murlasits, Z. et al, (2018م) (24) بدراسة بعنوان "التأثيرات الفسيولوجية المستخلصة من تدريب القوة والتحمل المتزامن".

هدفت الدراسة إلى التعرف على التأثيرات الحادثة نتيجة إستخام التدريب المتزامن للقوة والتحمل

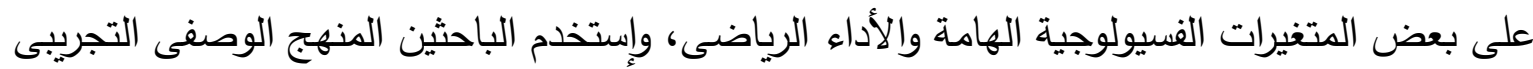

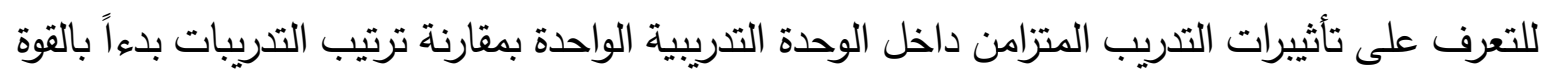

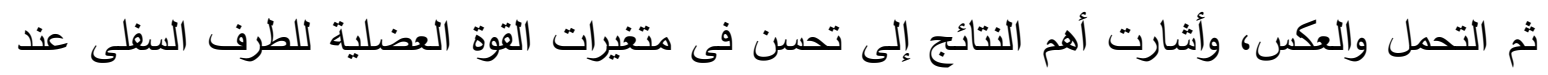

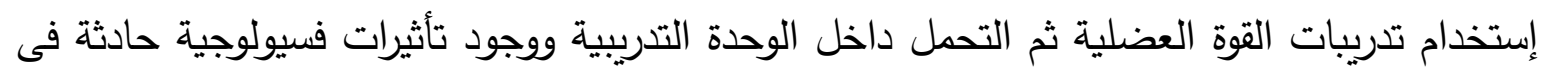

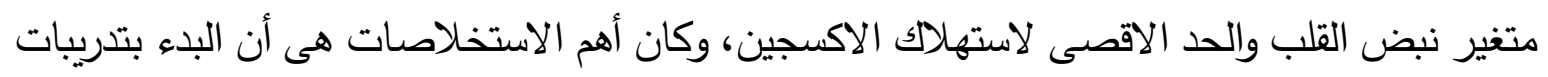

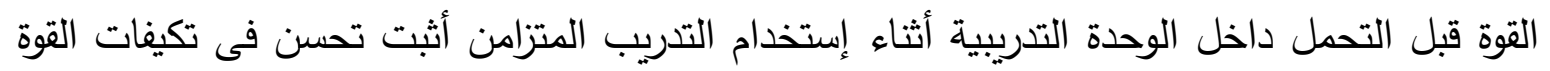
العضلية بالثدات المنخفضة.

2/2/2 قام جوأيين روبينو وآخرون Robineau, J. et al, (2016م) (30) بدراسة بعنوان "آثار التدريب

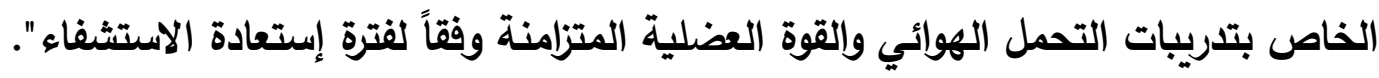
هدفت الدراسة إلى التعرف على التأثيرات المصاحبة لتدريب التحمل الهوائى والقوة العضلية بعد فترات راحة بين وحدات التدريب المتزامن يبلغ توقيتاتها (بدون راحة، 6 ساعات، 24 ساعة)، وإستخدام

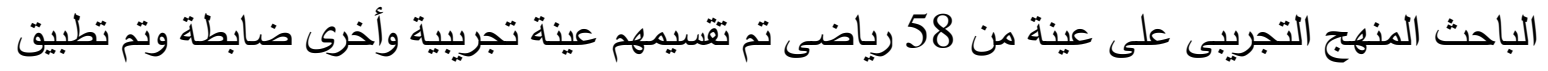

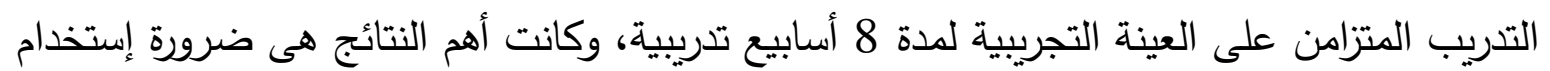

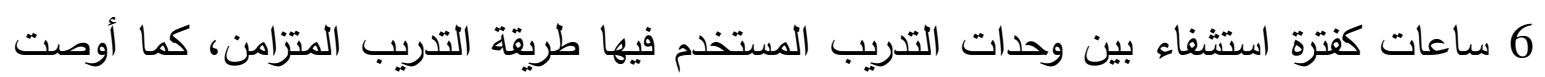
الدراسة بضرورة إستخدام طريقة التدريب المتزامن بما لا يزيد عن 2 - 3 وحدات تدريبية فى الأسبوع.

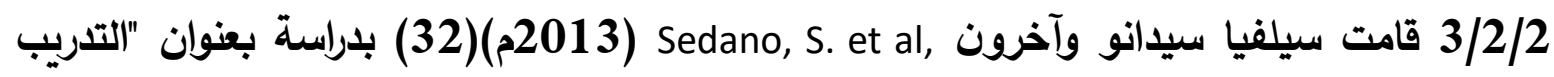
المتزامن لعدائي النخبة: العلاقة بين تدريب القوة والتحمل على مخرجات الأداء". 
هدفت الدراسة إلى التعرف على العلاقة بين تدريب القوة والتحمل على مخرجات الأداء للعدائين، استخدم البحث المنهج التجريبي لثلاث مجموعات (تدريب تحمل فقط - تدريب قوة المقاومة وبيومترك التك - تدريب متزامن بين القوة بأحمال 40٪ والتحمل)، شارك في الدراسة (18) لاعب، أشارت أهم النتائج

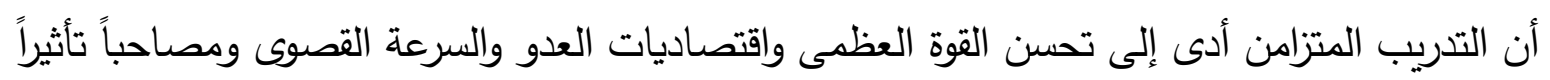

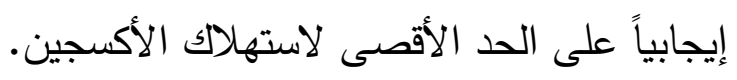

4/2/2 قامت مارتا وآخرون Marta, C. et al, (173) (12013) بدراسة بعنوان "تأثير التدريب المتزامن على القوة العظمى والحد الأقصى لاستهلاك الأكسجين للأطفال ما قبل المراهقة" العانة.

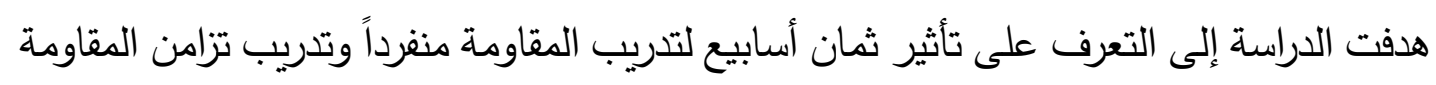

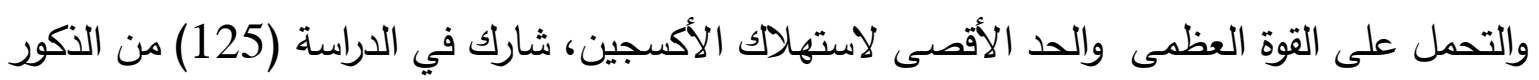

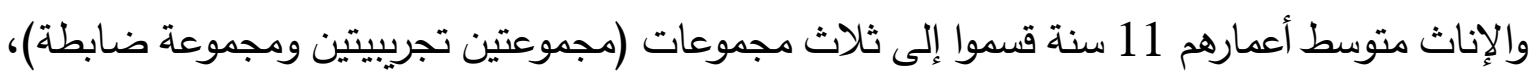
أشارت أهم النتائج إلى تحسن الوثب العمودي تحسن متوسط والحد الأقصى لاستهلاك الأكسجين، بينما

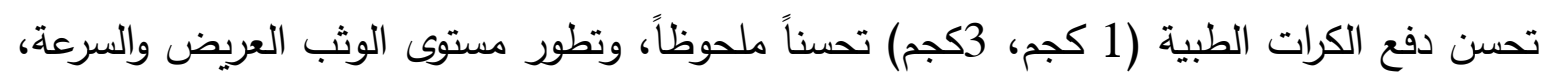

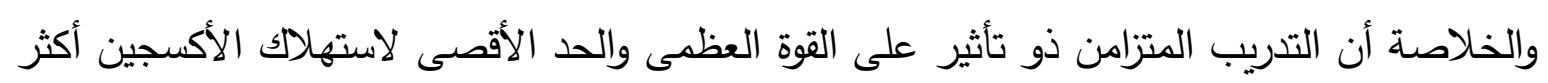
من التدريب بالمقاومة.

5/2/2 قام كريستوس بالابانس وآخرون . Balabinis, C. P et al (2003م)(9) بدراسة بعنوان "التغيرات المبكرة لتزامن تدريب القوة وإلتحمل".

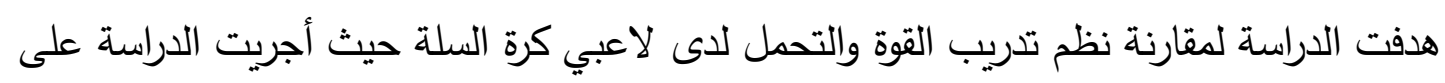

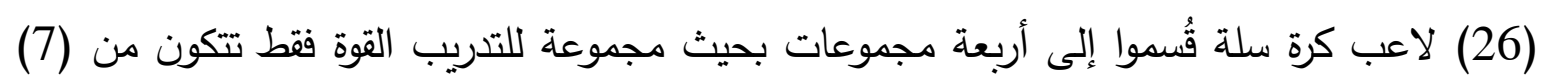

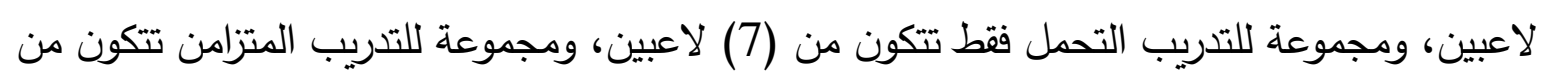
(7) لاعبين، ومجموعة ضابطة تتكون من (5) لاعبين. خضعت المجموعات التدريبية لبرنامج تدريبي

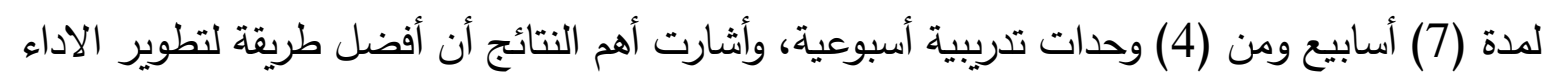

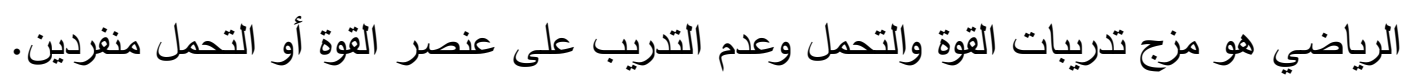

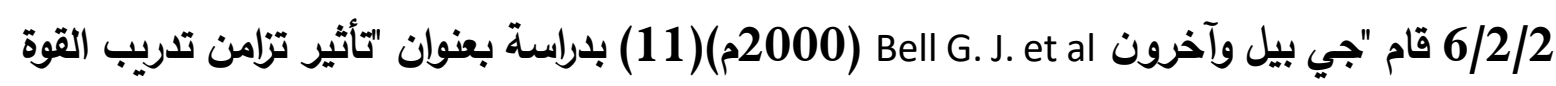
وإلتحمل على خصائص العضلات الهيكلية وتركيز الهرمونات".

هدفت الدراسة إلى التعرف على تأثير تزامن تدريب القوة والتحمل على خصائص العضلات الهيكلية وتركيز الهرمونات، أجريت الدراسة على (45) بالغ من الذكور والاناث قسموا إلى أربعة مجموعات بحيث مجموعة لتدريب القوة فقط، ومجموعة لتدريب التحمل فقط، ومجموعة للتدريب المتزامن (القوة والتحمل)، ومجموعة ضابطة. خضعت المجموعات لبرنامج تدريبي لمدة (12) أسبوع بحيث

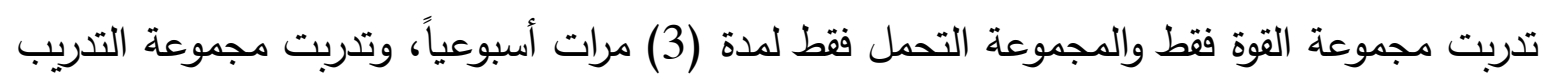


المتزامن لمدة (6) مرات أسبوعياً. تم عمل اختبارات في الاسبوع السادس والثاني عشر للمجموعات.

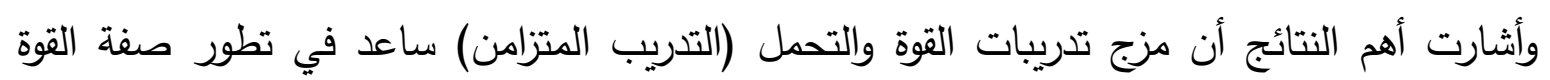
العضلية وبعض التكيفات العضلية الأخرى.

$$
\text { 1/3 منهج البحث: اءتات البحث: }
$$

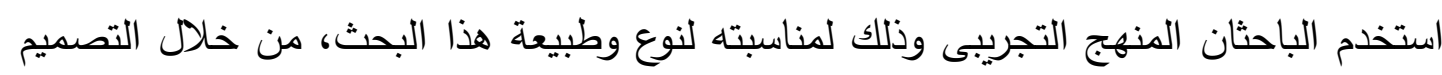
التجريبي المجموعة التجريبية والمجموعة الضابطة، باستخدام القياسين القبلي والبعدي، بهدف التعرف على تأثير البرنامج التدريبي.

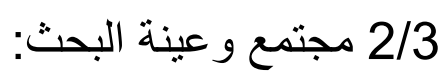

يمثل مجتمع البحث لاعبى أندية فرق كرة السلة تحت (20) سنة بمحافظة الشرقية وعددهم (6)

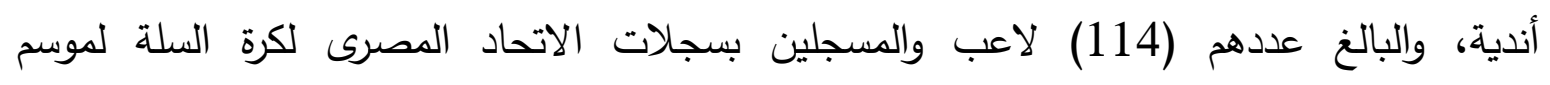
2020/2019

قام الباحثان باختيار عينة البحث بالطريقة العدية من لاعبى كرة السلة بمركز شباب ناصر

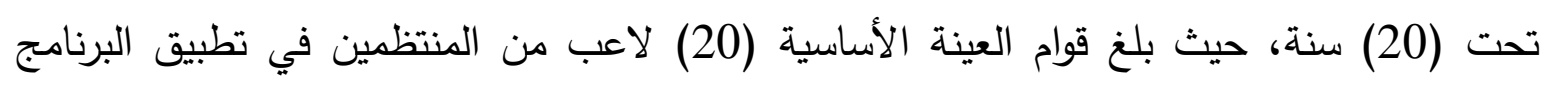

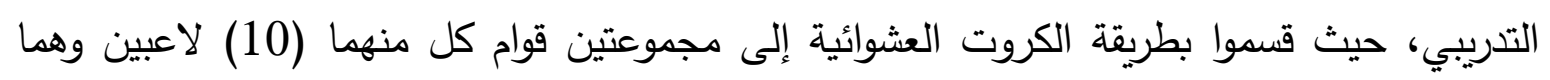
المجموعة التجريبية (التدريب المتزامن) والمجموعة الضابطة، حيث قام الباحثان بإجراء القياسات القبلية

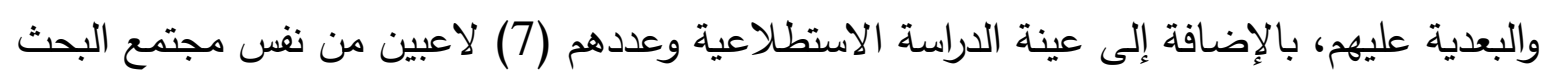

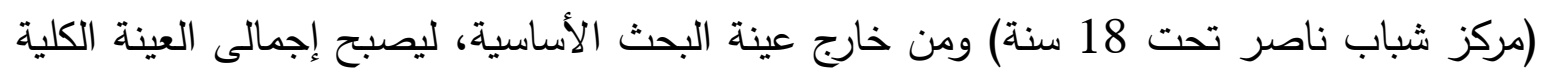

$$
\text { (27) لاعب (العينة الأساسية + العينة الاستطلاعية). }
$$

تم اختيار عينة البحث وفقاً للشروط التالية:

o الإنتظام في التدريب وعدم الإنقطاع حتى وقت تطبيق الدراسة الأساسية. م خلو أفراد العينة من الاصابات، وموافقة عينة البحث على المشاركة في الدراسة. م لايقل العمر التدرببى عن 8 سنوات. 1/2/3 خصائص عينة البحث:

تم حساب معامل الألتواء بدلالة كل من المتوسط الحسابى والوسيط والأنحراف المعيارى لعينة

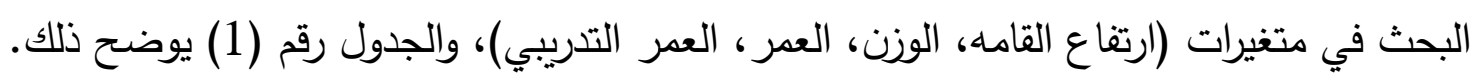

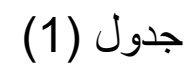

(27)

التوصيف الإحصائى للعينة الكلية في متغير (1ات النمو والعمر التدريبي 


\begin{tabular}{|c|c|c|c|c|c|}
\hline الالتواء & الوسيط & الانحراف & الحسابي & وحدة القياس & المتغيرات \\
\hline $0.43-$ & 1.82 & 0.07 & 1.81 & متر & ارتفاع القامه \\
\hline 0.64 & 75.30 & 4.20 & 76.20 & كجم & الوزن \\
\hline $0.59-$ & 18.80 & 1.02 & 18.6 & سنة & العمر الزمني \\
\hline $1.73-$ & 8.35 & 1.30 & 7.6 & سنة & العمر التدربيجي \\
\hline
\end{tabular}

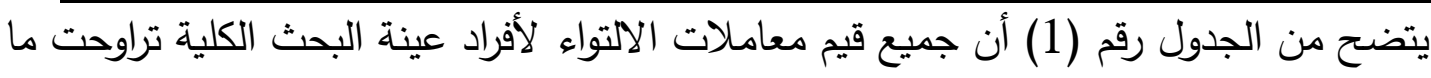

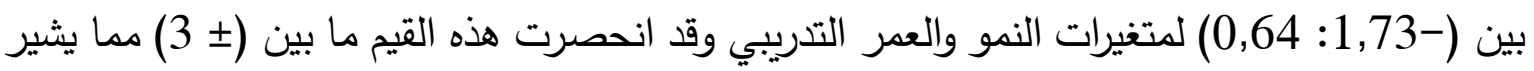
إلى وقوع عينة البحث الكلية داخل المنحنى الاعتدالى لهذه المتغيرات، وهذا يدل على التى تجانس ألفان أفراد العينة في هذه المتغيرات. 2/2/3 تجانس عينة البحث في المتغير ات البدنية والمهارية قبد البحات البحث:

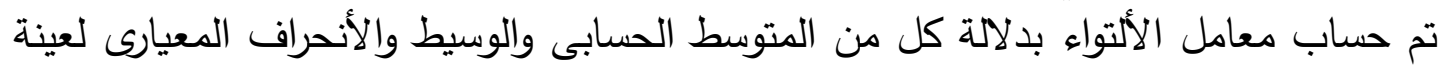

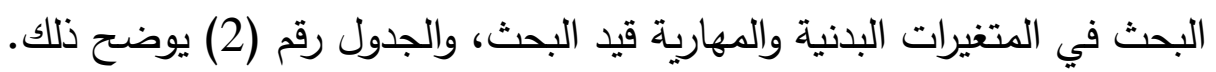

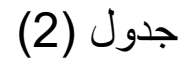
التوصيف الإحصائي للعينة الكلية في المتغيرات البدنية والمهارية قيد البحث (27) $=$ ن

\begin{tabular}{|c|c|c|c|c|c|c|c|}
\hline الالتواء & الوسيط & المعياري & الحسابي & وحدة القياس & \multicolumn{3}{|c|}{ المتغيرات } \\
\hline 0.22 & 3.00 & 0.68 & 3.05 & ث & \multicolumn{2}{|c|}{ السرعة الإنتقالية } & \\
\hline 0.20 & 70.90 & 4.50 & 71.20 & كجم & \multicolumn{2}{|c|}{ تحمل القوة (للرجلين) } & \\
\hline 0.65 & 31.24 & 5.70 & 32.48 & كجم & \multicolumn{2}{|c|}{ تحمل القوة (للذراعين) } & \\
\hline $0.49-$ & 23.78 & 6.20 & 22.77 & 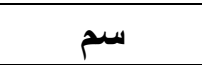 & \multicolumn{2}{|c|}{ القدرة العضلية للرجلين } & . \\
\hline $1.17-$ & 3.18 & 0.46 & 3.00 & ث & أفضل زمن (الزمن النموذجي) & \multirow{3}{*}{ القدرة على } & \\
\hline 0.38 & 38.64 & 3.67 & 39.10 & ث & مجموع الـ (12) تكرار & & . \\
\hline $0.44-$ & 8.50 & 1.36 & 8.30 & $\%$ & معدل فقد السرعة & & \\
\hline 0.86 & 44,20 & 4.35 & 44.45 & ملتر/كجم/ق & \multicolumn{2}{|c|}{ القدرة الهوائية (Vo } & \\
\hline $0.38-$ & 135.60 & 11.16 & 134.20 & $\dot{H}$ & \multicolumn{2}{|c|}{ تحمل القوة } & \\
\hline 1.03 & 6.00 & 1.16 & 6.40 & عدد & \multicolumn{2}{|c|}{ التصويب المتعدد للرمية الحرة } & \\
\hline $0.19-$ & 15.25 & 2.34 & 15.10 & عدد & \multirow{2}{*}{\multicolumn{2}{|c|}{ التصويب من أسفل السلة }} & \\
\hline $0.27-$ & 19.35 & 1.68 & 19.20 & $\dot{H}$ & & & \\
\hline 0.04 & 54,90 & 7.20 & 55 & عدد & \multicolumn{2}{|c|}{ المساعدة الدفاعية } & \\
\hline
\end{tabular}

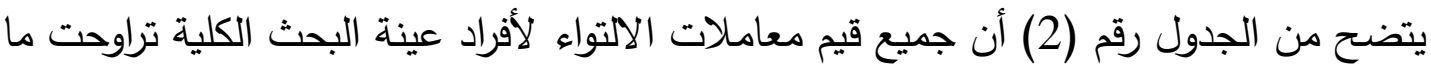

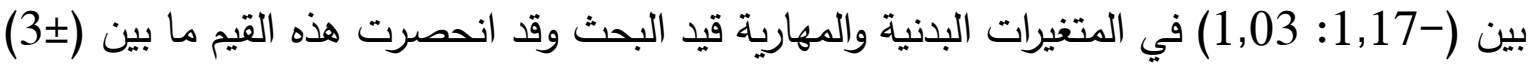

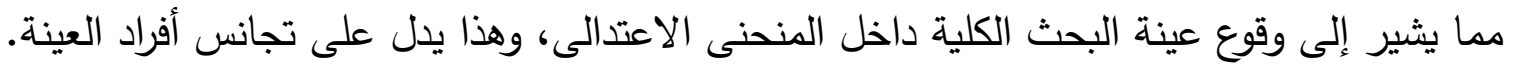
3/3 وسائل و أدوات وأجهزة جمع البحت البيانات: 1/3/3 استمار ات جمع البيانات: 
1/1/3/3 استمارة لتسجيل البيانات الخاصة بعينة البحث وأشتملت على متغيرات (ارتفاع القامه، الوزن،

$$
\text { العمر ، العمر التدريبي). }
$$

2/1/3/3 استمارة جمع البيانات الخاصة بالاختبارات البدنية والمهارية والقياسات قيد البحث.

2/3/3 الأدوات والأجهزة المستخدمة:

Restamer Pe 3000 لقياس ارتفاع القامة.

2/2/3/3 ديزان طبي معاير لقياس الوزن.

3/2/3/3 شريط قياس (متر) + شريط لاصق ملون.

4/2/3/3 ملعب كرة سلة قانونى + كرات سلة + أقماع.

5/2/3/3 أثقال حرة، بار حديدي، صالة جيم.

6/2/3/3 كاميرا فيديو ذات سرعة من 25 حتى 100 كادر / ثانية من نوع Fujifilm HS30 لحساب صئم الأزمنة.

Sport mat 7/2/3/3 سجادة التمارين الرياضية الريانية

8/2/3/3 اسطوانة مدمجة لاختبار التحمل الهوائى (20 m Multistage Fitness Test /3/3/3 تحديد المتغير ات و الإختبار ات الخاصة بالبة البحث:

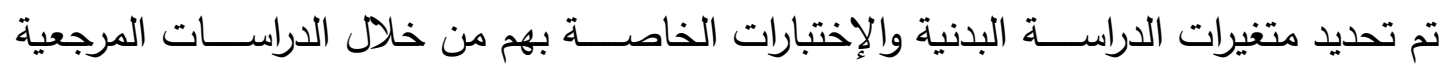

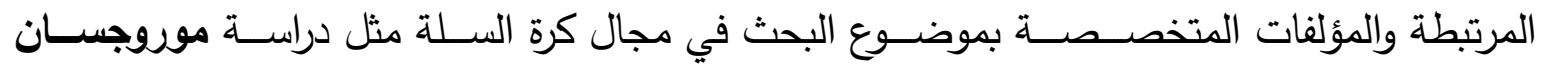
Murugesan, T.

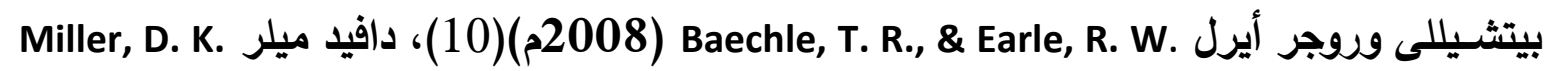

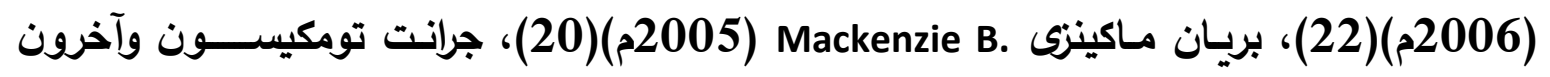
Fitzsimons M. et al Tomkinson, G.R. et al .(14)(1993)

كما تم تحديد متغيرات الدراسة المهارية والإختبارات الخاصة بهم من خلال الدراسات المرجعية

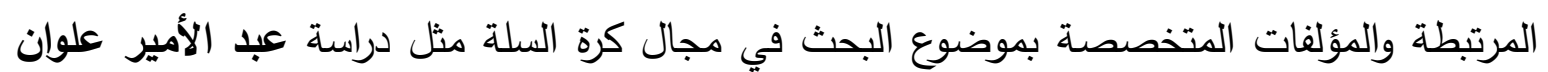
وآخرون (2010م)(1)، محمد عبد الدايم وصبحي حسانين (1999م)(6)، (6)، فيليب سانتانا وآخرون Mitova, O., \& Sidorenko, Santana, F. L. et. al

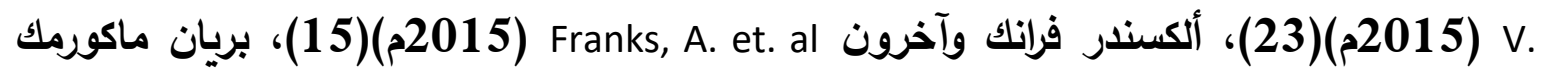

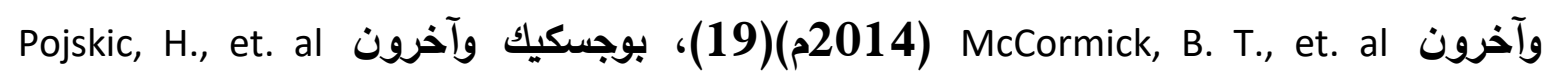

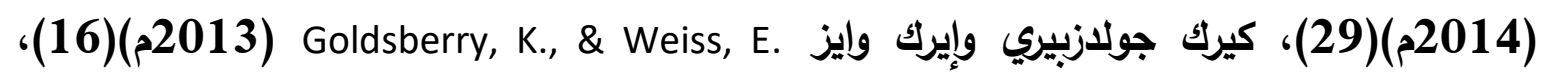
هيروكي أكوبو ومونت هوبارد Okubo, H., \& Hubbard, M. Algendy T.

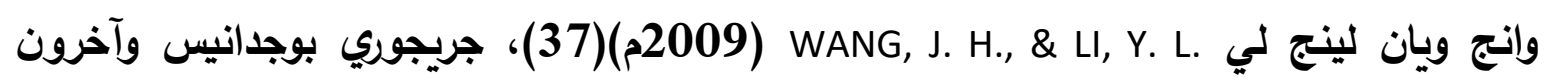


Yong-dong, Bogdanis, G. C. et al. .(40)(2005)G.

تم تحديد أهم المتغيرات البدنية والمهارية والاختبارات الخاصـة بقياس المتغيرات البدنية والمهارية قيد البحث والمرتبطة بكرة السلة وفق ما يلي: 1/3/3/3 المتغير ات و الاختبار ات البدنية: م اختبار تحمل القوة (10/3/3/ أقصى تكرار للرجلين) (10 RM Leg Squat). م اختبار تحمل القوة (10 أقصى تكرار للذراعين) (10 RM Bench Press). o اختبار القدرة العضلية للرجلين (الوثب العمودي) (Vertical Jump Test). O اختبار السرعة الإنتقالية (العدو 20 متراً من البدء العالي) (20 - Meter Dash Test). م اختبار القدرة على تكرار السرعة (تحمل السرعة) (Repeated Sprint Ability). o ا متبار بيب لقياس القدرة الهوائية (20m Multistage Fitness Test) (Vo

م اختبار التحمل العضلي (تحمل القوة) (Core Muscle Strength and Stability). مرفق (1). 2/3/3/3 المتغير ات و الاختبار ات المهارية:

م اختبار التصـــويب المتعدد للرمية الحرة لمدة 60 ثانية

\section{.shooting test}

o اختبار التصويب من أسفل السلة Under Basket Shot. O اختبار التحرك الدفاعي. O اختبار سرعة قطع الكرة (المساعدة الدفاعية). مرفق (2/3). 4/3 الدراسة الاستطلاعية:

قام الباحثان بعدد من الإجراءات للتأكد من مدى مناسبة الاختبارات قيد البحث والتى اسفر عنها

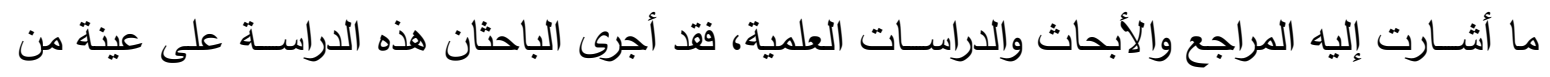

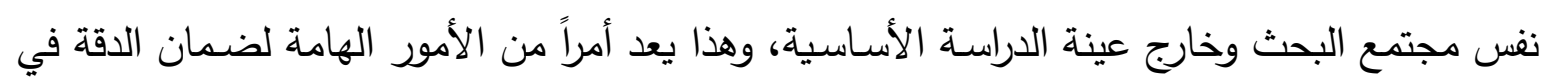

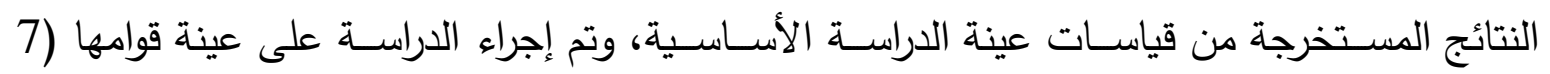
ناشئين) من نفس مجتمع البحث. 1/4/3 أهداف الدراسة:

م التأكد من تدريب الدساعدين وكذلك توضيح طبيعة الادوار التى يكلف بها المساعدين اثناء تطبيق

$$
\text { محتوى الوحدات التدريبية. }
$$

م اكتثاف نواحى القصور والضعف والعمل على تلاشى الاخطاء المحتمل ظهورها اثثاء إجراء الدراسة الاساسية وعلى الصعوبات التى قد تواجه الباحثان عند تنفيذ البحث. م التأكد من صلاحية الأجهزة والأدوات المستخدمة. O مدى ملائمة التدريبات قيد البحث لعينة البحث.

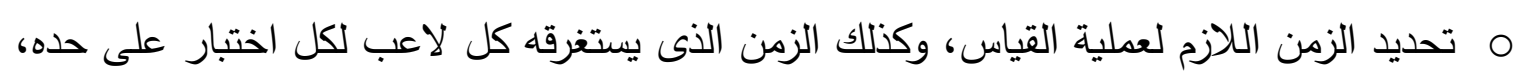
وذلك لتحديد المدة المستغرقة في تتفيذ الاختبارات والقياسات. 
O ترتيب سير الاختبار قيد البحث لعينة البحث.

1/2/4/3 المعاملات العلمية للاختبار ات:

1/1/2/4/3 إيجاد معامل الصدق:

لإيجاد معامل الصـــق قام الباحثان بتطبيق صــــ التمايز ، على مجموعتين من ناشـئ عينة

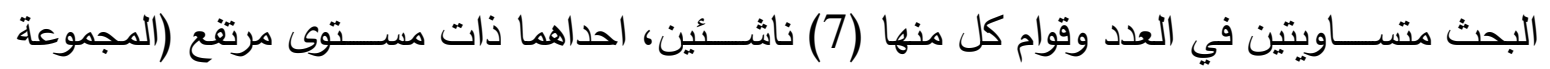

المميزة) وهم لاعبى فريق تحت (20) سنة من مركز شباب ناصر ، والمجموعة الاخرى (غير المميزة)

تمثل فريق تحت (20) سنة من مركز شباب بحري.

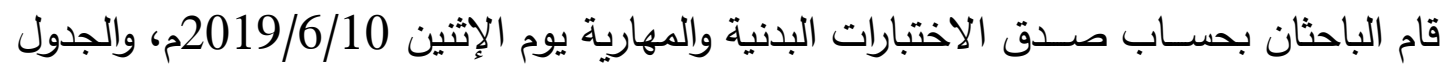

(3) يوضح دلالة الفروق بين المجموعتين المميزة والغير مميزة.

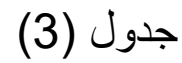

دلالة الفروق بين المجمو عتين غير المميزة والمميزة للعينة الاسنطلاعية في المتغيرات البدنية

و المهارية قيد البحث (صدق الاختبار)

$7=2 ن=1 ن$

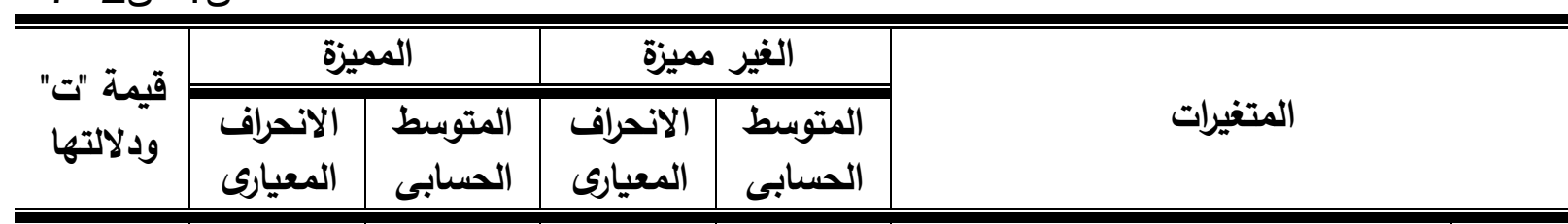

\begin{tabular}{|c|c|c|c|c|c|c|c|}
\hline$* 3.100$ & 0.67 & 4.1 & 0.27 & 7.67 & \multicolumn{2}{|c|}{ السرعة الإنتقالية } & \\
\hline *3.332 & 3.95 & 72.25 & 2.61 & 68.10 & \multicolumn{2}{|c|}{ تحمل القوة (للرجلين) } & \\
\hline *3.099 & 5.20 & 33.53 & 4.88 & 29.38 & \multicolumn{2}{|c|}{ تحمل القوة (للذاعين) } & \\
\hline$* 5.850$ & 6.06 & 23.82 & 5.90 & 19.67 & \multicolumn{2}{|c|}{ القدرة العضلية للرجلين } & \\
\hline$* 3.415$ & 0.17 & 4.05 & 0.26 & 5.13 & أفضل زمن (الزمن النموذجي) & \multirow{3}{*}{ القدرة على } & \\
\hline$* 4.550$ & 3.22 & 40.15 & 3.00 & 36.78 & مجموع الـ (12) تكرار & & \\
\hline *3.507 & 1.33 & 9.35 & 1.28 & 12.64 & معدل فقد السرعة & & \\
\hline$* 4.500$ & 4.03 & 46.49 & 3.95 & 41.62 & \multicolumn{2}{|c|}{ القدرة الهوائية (Vo2max) } & \\
\hline$* 3.658$ & 9.88 & 135.25 & 8.65 & 122.35 & \multicolumn{2}{|c|}{ تحمل القوة } & \\
\hline$* 4.621$ & 1.23 & 7.45 & 1.20 & 4.68 & \multicolumn{2}{|c|}{ التصوبب المتعدد للرمية الحرة } & \\
\hline$* 4.489$ & 2.11 & 16.15 & 2.15 & 12.40 & \multicolumn{2}{|c|}{ التصوب من أسفل السلة } & \\
\hline *5.327 & 1.47 & 20.25 & 1.34 & 34.65 & \multicolumn{2}{|c|}{ التحرك الدفاعي } & \\
\hline$* 3.650$ & 6.85 & 56.05 & 5.68 & 51.30 & \multicolumn{2}{|c|}{ المساعدة الدفاعية } & \\
\hline
\end{tabular}

قيمة "ت" الجدولية عند مستوى 0.05 ودرجات حرية 12 = 2.179

يتضح من الجدول رقم (3) وجود فروق ذات دلالة إحصائية في المتغيرات البدنية والمهارية قيد

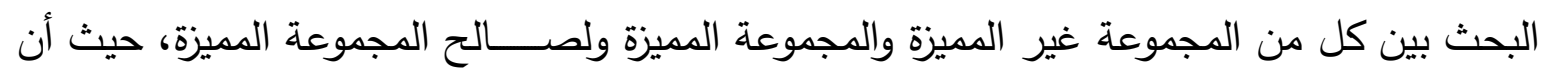

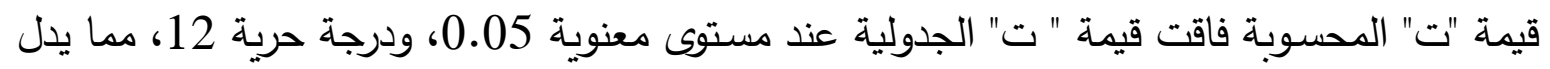

على صدق نتائج الاختبارات البدنية والمهارية قيد البحث، وهذا يعنى قدرة هذه الاختبارات على التمييز

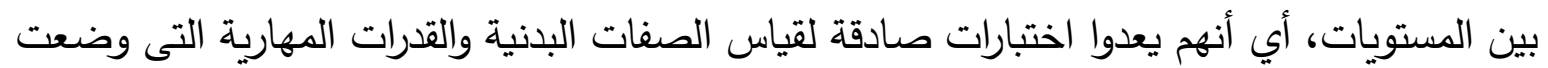


تم إيجاد معامل الثبات عن طريق قيام الباحثان بتطبيق الاختبار ثم إعادة تطبيقه مرة أخرى على عينة قوامها (7) ناشـئين من افراد العينة الاســطلاعية (لاعبى فريق تحت 20 ســنة من مركز

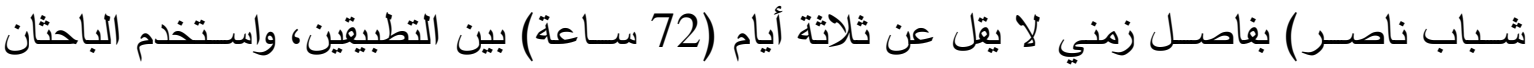

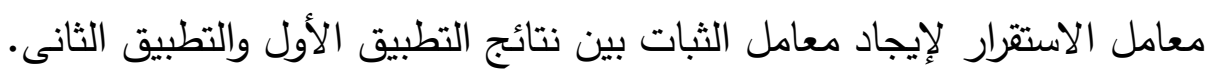
قام الباحثان بحسـاب معامل ثبات الاختبارات البدنية والمهارية خلال الفترة من 2019/6/10م، 2019/6/15م، والجدول (4) يوضح معامل ثبات الاختبارات البدنية والمهارية.

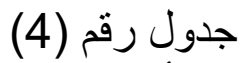

دلالة الفروق ومعامل الاستقرار بين التطبيق الأول والثانى للعينة الاستطلاعية في الاختبارات البدنية

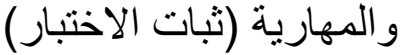

\begin{tabular}{|c|c|c|c|c|c|c|c|}
\hline \multirow{2}{*}{ الاستقرار } & \multicolumn{2}{|c|}{ التطبيق الثانى } & \multicolumn{2}{|c|}{ التطبيق الأول } & \multirow{2}{*}{\multicolumn{3}{|c|}{ المتغيرات }} \\
\hline & الحستوسيى & الحسابى المتوسط & المعيارى & الحسابى & & & \\
\hline *0.897 & 0.88 & 4.02 & 0.67 & 4.1 & \multicolumn{2}{|c|}{ السرعة الإنتقالية } & \\
\hline$* 0.902$ & 3.64 & 71.68 & 3.95 & 72.25 & \multicolumn{2}{|c|}{ تحمل القوة (للرجلين) } & \\
\hline$* 0.799$ & 5.10 & 33.90 & 5.20 & 33.53 & \multicolumn{2}{|c|}{ تحمل القوة (للذاعين) } & \\
\hline *0.858 & 6.00 & 24.54 & 6.06 & 23.82 & \multicolumn{2}{|c|}{ القدرة العضلية للرجلين } & $q$ \\
\hline *0.869 & 0.22 & 4.08 & 0.17 & 4.05 & فضل زمن (الزمن النموذجي) & القدرة على & \\
\hline *0.787 & 3.18 & 39.88 & 3.22 & 40.15 & مجموع الـ (12) تكرار & تكرار. & 雪。 \\
\hline$* 0.916$ & 1.11 & 8.90 & 1.33 & 9.35 & معدل فقد السرعة & ال - السرعة & \\
\hline$* 0.855$ & 4.31 & 45.87 & 4.03 & 46.49 & \multicolumn{2}{|c|}{ القدرة الهوائية (Vo2max) } & \\
\hline$* 0.831$ & 10.10 & 133.58 & 9.88 & 135.25 & \multicolumn{2}{|c|}{ تحمل القوة } & \\
\hline *0.901 & 1.56 & 6.95 & 1.23 & 7.45 & \multicolumn{2}{|c|}{ التصويب المتعدد للرمية الحرة } & \\
\hline$* 0.890$ & 2.10 & 15.77 & 2.11 & 16.15 & \multicolumn{2}{|c|}{ التصويب من أسفل السلة } & \\
\hline *0.878 & 1.64 & 19.10 & 1.47 & 20.25 & \multicolumn{2}{|c|}{ التحرث الدفاعي } & \\
\hline$* 0.905$ & 5.63 & 55.50 & 6.85 & 56.05 & \multicolumn{2}{|c|}{ المساعدة الدفاعية } & \\
\hline
\end{tabular}

0.755 = قيمة "ر" الجدولية عند مستوى 0.05 ودرجات حرية 5 وداعة

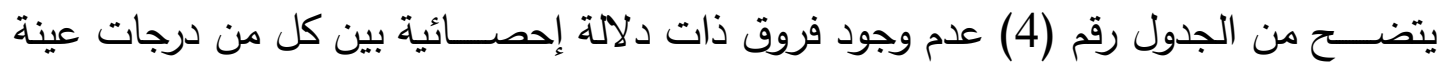

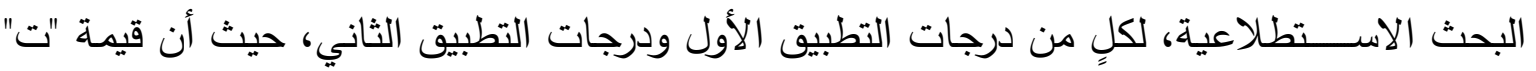

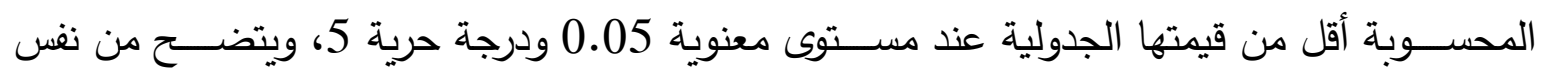

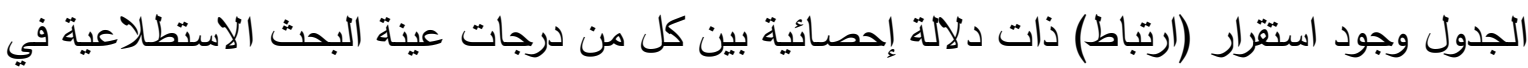

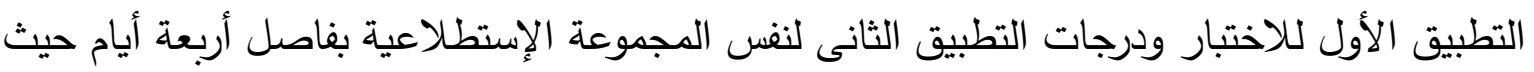

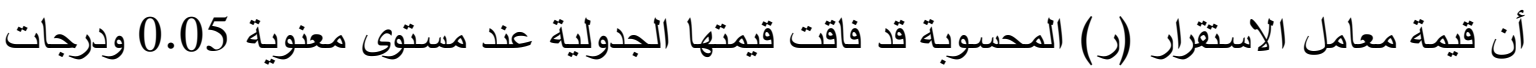
حرية 5، وهذا يعنى ثبات درجات الاختبار عند إعادة تطبيقه تحت نفس الظروف مرة أخرى. 
5/3 تطبيق تجربة البحث:

1/5/3 إعداد البرنامج التدريبي:

بعد إجراء القياسات القبلية للمتغيرات قيد البحث وجمع البيانات الأولية و تحليل محتوى المراجع العلمية العربية والأجنبية والدراسات المرتبطة بمتغيرات البحث تمكن الباحثان من تصميم البرنامج

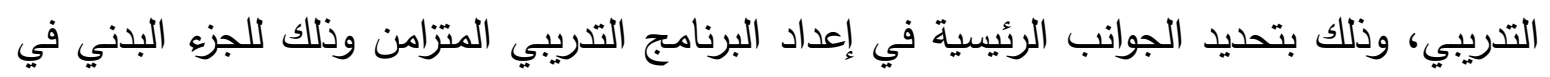
فترة الإعداد العام والخاص الخاص لناشئي كرة السلة تحت 20 سنة. 1/1/5/3 هدف البرنامج التدريبي: يهدف البرنامج التدريبي المتزامن إلي إحداث طفرة تتموية حقيقية في بعض الدكونات البندية والمهارية لناشئي كرة السلة تحت 20 سنة.

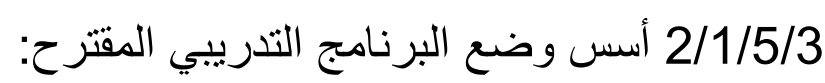
من خلال أراء بعض المراجع المتخصصة فى التدريب الرياضي والتي تناولت أسس التدريب،

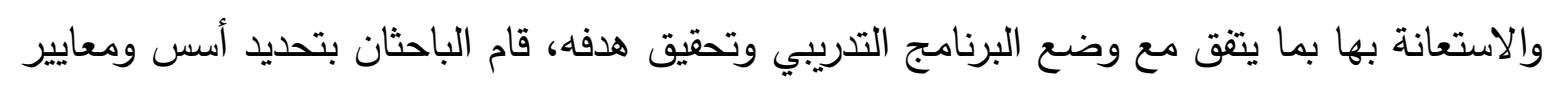
وضع البرنامج والتي تمثلت في النقاط التالية: م ملاءمة البرنامج التدريبى مع الأهداف الموضوعة. O مرونة البرنامج وقابليته للتعديل. O م توفير الإمكانيات المستخدمة.

o ملائمة البرنامج التدريبى للمرحلة السنية وخصائص النمو ومستوى العينة. م مراعاة الفروق والاستجابة الفردية بتحديد المستوى لكل فرد داخل العينة. م تحديد شدة وحجم التدريبات وفترات الراحة البينية وفقاً لمبادئ تقنين الأحمال التدريبية. م تحديد زمن وعدد الوحدات التدريبية اليومية.

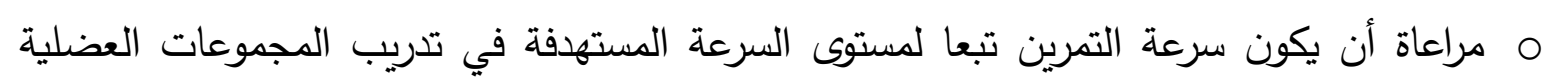

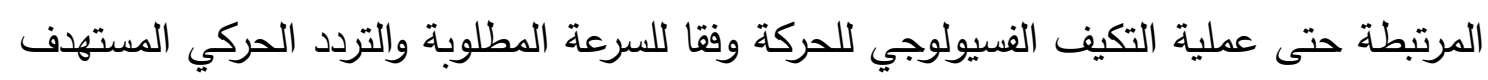
والقوة الداعمة لتطوير جميع عناصر الحركة من حيث لئ (الانقباض - الانبساط).

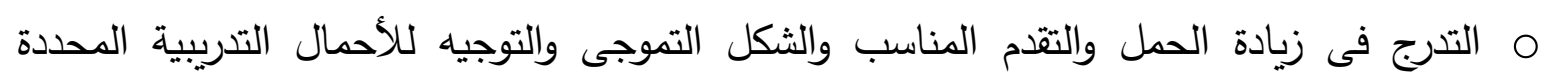
وديناميكية الأحمال التدريبية. م طريقة التدريب المستخدمة هى طريقة التدريب الفترى منخفض ومرتفع الثدة. O مراعاة الأسس الرياضية الفسيولوجية للبرنامج التدريبي المقترح وهي فترة الإحماء ثم الجزء الرئيسي منئي ثم التهائة. 3/1/5/3 خطوات وضع البرنامج التدريبي المقترح: 
قام الباحثان بعمل مسح مرجعي للدراسات المرجعية والمرتبطة بموضوع الدراسة الحالية ومتغيراتها وذلك للتعرف على مدة البرامج التدريبية الموضوعة ونوعية التدريبات المستخدمة وحجم العينات وأهم

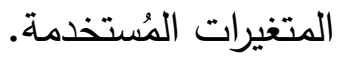

يحتوى البرنامج التدريبي المقترح على مجموعة من التمرينات لتطوير بعض متغيرات القوة العضلية

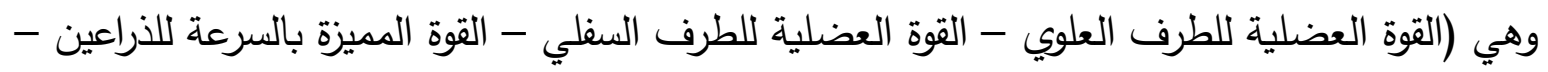
القوة المميزة بالسرعة للرجلين)، وبعض متغيرات التحمل العضلي وهي (تحمل السرعة - تحمل تغير

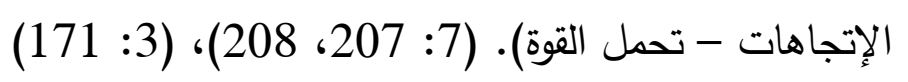

ويتضح من الجدول (5) أن البرامج التدريبية الموضوعة تراوحت مدتها من ستة أسابيع إلى إثنى

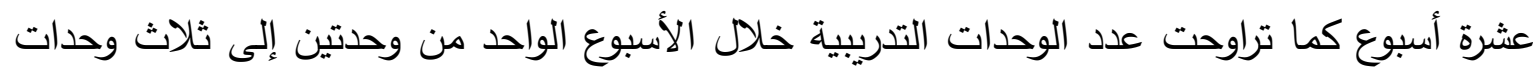

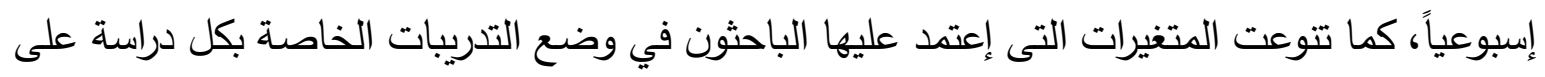
حدة، كما تراوح السن من (11) عام إلى (84) عام للعينة المستخدمة، وتتوعت ما بين الذكور والإناث.

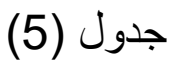

المسح المرجعي لتحديد مدة البرنامج التدريبي و التمرينات المستخدمة

\begin{tabular}{|c|c|c|c|c|c|c|}
\hline عدد الوحدات & البرنامج & 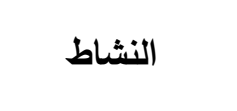 & 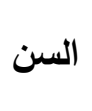 & العينة العة & إسم المؤلف & b \\
\hline 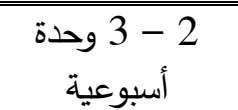 & $10-6$ & (سلة/قداضم/رجبين) & 20 & 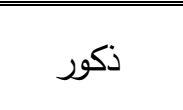 & (24)(2018) Murlasits, Z. et al & 1 \\
\hline 3 وحدة أسبوعية & ا 8 & كرة سلة & 20 & ذكور & (25)(2018) Murugesan, T. & 2 \\
\hline 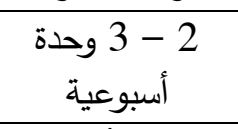 & 8 أسابيع & رياضيين & 22 & 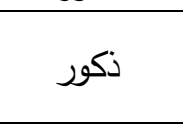 & (30)(2016) Robineau, J. et al. & 3 \\
\hline 2 وحدة أسبوعية & 12 أسبوع & عدائين & 24 & ذكور & (32)(2013) Sedano, S. et al. & 4 \\
\hline 2 وحدة أسبوعية & 8 & كرة سلة & 11 & ذكور وإناث & (17)(2013) Marta, C. et al. & 5 \\
\hline 3 وحدة أسبوعية & 8 أسبوع & رياضيين & 22 & ذكور & $\begin{array}{l}\text { Aagaard, P., \& Andersen, J. L. } \\
(8)(2010)\end{array}$ & 6 \\
\hline
\end{tabular}

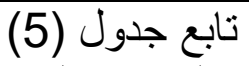

المسح المرجعي لتحديد مدة البرنامج التدريبي و التمرينات المستخدمة

\begin{tabular}{|c|c|c|c|c|c|c|}
\hline 3 وحدة أسبوعية & 8 & أصحاء & 20 & ذكور & $\begin{array}{c}\text { Baechle, T. R., \& Earle, R. W. } \\
(10)(2008)\end{array}$ & 7 \\
\hline 4 وحدة أسبوعية & 7 أسابيع & كرة سلة & 20 & ذكور & (9)(2003)Balabinis, C. P et al. & 8 \\
\hline 3 وحدة أسبوعية & 10 أسبابيع & رياضيين & 26 & ذكور & (18)(2002) McCarthy, P. et al. & 9 \\
\hline 3 وحدة أسبوعية & 12 أسبوع & 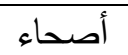 & $84-60$ & ذكور واناث & (39)(2001) Wood, R. H. et al. & 10 \\
\hline
\end{tabular}

4/1/5/3 محددات البرنامج التدريبى: 1/4/1/5/3

1/4/1/5/3 مكونات الوحدة التدريبية:

م الجزء التمهيدي (الأحماء). 


$$
\begin{aligned}
& \text { O الجزء الرئيسي (البدني - المهاري - الخططي). }
\end{aligned}
$$

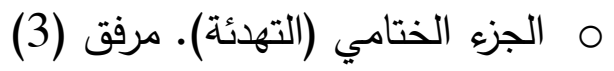

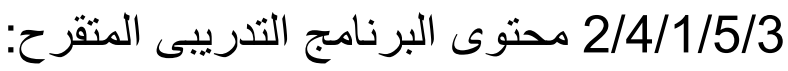

$$
\begin{aligned}
& \text { م مدة تتفيذ البرنامج التدريبي الكقترح (8) أسابيع. }
\end{aligned}
$$

م عدد الوحدات التدريبية اليومية خلال الأسبوع بواقع (3) وحدات تدريبية، ليكون إجمالي الوحدات

$$
\text { التدريبية (24 وحدة تدريبية). }
$$

$$
\text { م زمن الوحدات التدريبية (90 دقيقة)، بإجمالى زمن البرنامج التدريبي (36 ساعة). }
$$

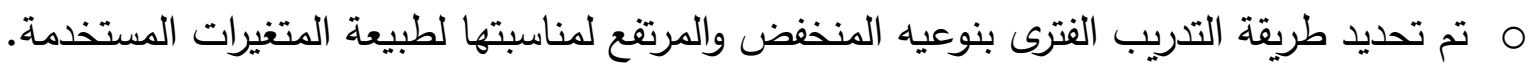

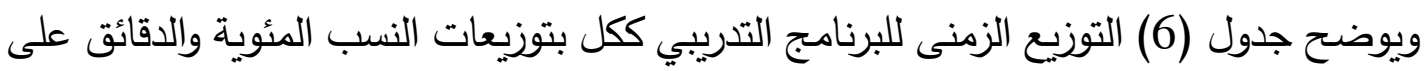
الأسابيع التدريبية.

\begin{tabular}{|c|c|c|c|c|c|c|c|c|c|c|}
\hline \multirow{2}{*}{ الاجمالي } & \multicolumn{2}{|c|}{ الإعدافاد ماقبل } & \multicolumn{4}{|c|}{ الاعداد الخاص } & \multicolumn{2}{|c|}{ الاعداد العام } & \multicolumn{2}{|c|}{ مر احل الاعداد } \\
\hline & الثامن & السابع & السادس & الخامس & الر ابع & الثالث & الثاني الثي & الاول & \multicolumn{2}{|c|}{ الاسبوع } \\
\hline & & & & & & & & & حمل أقصى & \\
\hline & & - & & - & & & & & حمل أقلى من & .3 \\
\hline & - & & - & & - & & - & & حمل عالى & $f$ \\
\hline & & & & & & - & & - & حمل متوسط & \\
\hline
\end{tabular}

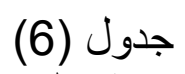

التوزيع الزمني بالنسبة المئوية و الدقائق للبرنامج التدريبي ككل

\begin{tabular}{|c|c|c|c|c|c|c|c|c|c|c|c|}
\hline \multirow{3}{*}{ 240 ق } & \multicolumn{2}{|c|}{ البدنية والههارية القدات } & \multicolumn{4}{|c|}{ تنمية الققر ات البدنية والمهارية الخاصة } & \multicolumn{2}{|c|}{ 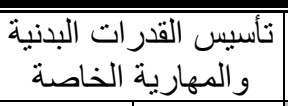 } & \multirow{2}{*}{\multicolumn{3}{|c|}{ هدف المرحلة }} \\
\hline & 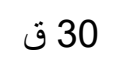 & - ال & 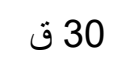 & 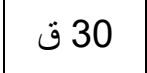 & 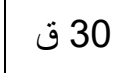 & 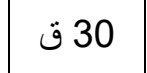 & - ما & 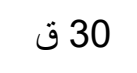 & & & \\
\hline & $\begin{array}{c}33.3 \\
\%\end{array}$ & $\begin{array}{c}33.3 \\
\%\end{array}$ & \% 28.8 & \% 28.8 & $\% 28.8$ & $\% 28.8$ & $\% 24.4$ & $\% 22.2$ & $\%$ & \multirow{2}{*}{ المهارى } & \multirow[b]{2}{*}{$\bar{\lambda}$} \\
\hline \multirow[t]{2}{*}{ ا } & 90 ق & 90 ق & 78 ق & 78 ق & 78 ق & 78 ق & 66 ق & 60 ق & دقيقة & & \\
\hline & $\begin{array}{c}44.4 \\
\%\end{array}$ & $\begin{array}{c}44.4 \\
\%\end{array}$ & $\% 48.8$ & \% 48.8 & $\% 48.8$ & $\% 48.8$ & $\% 53.3$ & \% 55.6 & $\%$ & \multirow{2}{*}{ البنى أل البزء } & 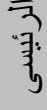 \\
\hline 1062 ق & 120 ق & 120 ق & 132 ق & 132 ق & 132 ق & 132 ق & 144 ق & 150 ق & دقيقة & & \\
\hline
\end{tabular}

تابع جدول (6)

التوزيع الزمني بالنسبة المئوية و الدقائق للبرنامج التدريبي ككل 


\begin{tabular}{|c|c|c|c|c|c|c|c|c|c|}
\hline 240 ق & 30 ق & 30 ق & 30 ق & 30 ق & 30 ق & 30 ق & 30 ق & 30 ق & الجزء الختامي \\
\hline 2160 ق & 270 ق & 270 ق & 270 ق & 270 ق & 270 ق & 270 ق & 270 ق & 270 ق & الاجمالى \\
\hline
\end{tabular}

6/3 - الدر اسة الأساسية:

1/6/3 القياس القبلي: القانية

قام الباحثان بتطبيق القياس القبلي على عينة البحث حيث تم تطبيق الاختبارات البدنية والمهارية

$$
\text { وذلكك يوم 19-2019/6/20م. }
$$

2/6/3 تطبيق البرنامج: 2/3

بعد التأكد من تجانس أفراد العينة قام الباحثان بتطبيق البرنامج التدريبي على عينة البحث، وذلك البكا

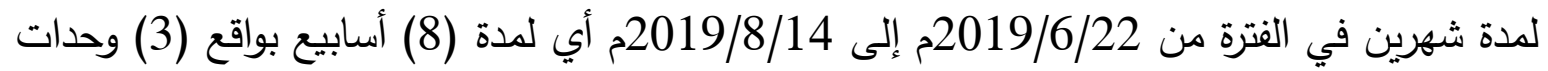
تدريبية أسبوعية هي أيام السبت والإثثين والأربعاء.

3/6/3 القياس البعدي:

تم إجراء القياس البعدي على المجموعة التجريبية قيد البحث، وبنفس الشروطوالتعليمات والظروف ومواصفات القياسات القبلية، وكذلك على نفس المتغيرات البدنية والمهارية وذلك بعد انتهاء مدة تطبيق

$$
\text { البرنامج. وذلك يوم 16-2019/8/17م. }
$$

7/3 المعالجات الإحصائية:

بعد جمع البيانات وتسجيل القياسات المختلفة للمتغيرات التى استخدمت في هذا البحث، تم إجراء

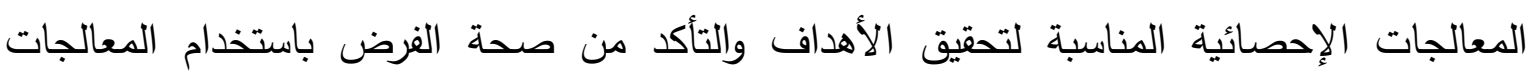
الإحصائية وكذلك الحاسب الآلى باستخدام البرنامج الإحصائى "Excel" التابع للحزمة البرمجية الموثقة

$$
\text { Microsoft Office }
$$

Skewness معامل الالتواء

O اختبار "ت"
Mean المتوسط الحسابي

Median الوسيط

Standard Deviation الانحراف المعياري

0/4 0/4 عرض ومناقثة النتائج:

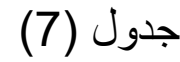

دلالة الفروق بين القياس القبلي و البعدي للمتغيرات البذنية و المهارية للمجموعة التجريبية قيد البحث ن 


\begin{tabular}{|c|c|c|c|c|c|c|c|}
\hline \multirow{3}{*}{ قديمة "ت" } & \multicolumn{2}{|c|}{ القياس البعدي } & \multicolumn{2}{|c|}{ القياس القبلي } & \multirow{3}{*}{\multicolumn{3}{|c|}{ المتغيرات }} \\
\hline & المتوسط & المتوسط & الانحراف & المتوسط & & & \\
\hline & الحسابى & الحسابى & المعيارى & الحسابى & & & \\
\hline$* 4.906$ & 0.55 & 3.85 & 0.67 & 4.1 & \multicolumn{2}{|c|}{ السرعة الإنتقالية } & \\
\hline$* 2.501$ & 3.15 & 74.76 & 3.95 & 70.92 & \multicolumn{2}{|c|}{ تحمل القوة (للرجلين) } & \\
\hline$* 5.100$ & 4.60 & 37.87 & 5.20 & 33.53 & \multicolumn{2}{|c|}{ تحمل القوة (للذراعين) } & \\
\hline$* 3.350$ & 5.40 & 29.67 & 6.06 & 23.82 & \multicolumn{2}{|c|}{ القدرة العضلية للرجلين } & \\
\hline$* 2.540$ & 0.21 & 3.50 & 0.35 & 3.74 & أفضل زمن (الزمن النموذجي) & \multirow{3}{*}{ القدرة على السرعة } & \\
\hline$* 4.906$ & 3.81 & 35.54 & 3.22 & 40.15 & مجموع الـ (12) تكرار & & 高 \\
\hline$* 4.531$ & 1.60 & 5.20 & 1.33 & 9.35 & معدل فقد السرعة & & \\
\hline$* 3.358$ & 4.12 & 48.57 & 4.03 & 46.49 & \multicolumn{2}{|c|}{ القدرة الهوائية (Vo2max) } & \\
\hline$* 4.135$ & 9.88 & 135.25 & 6.84 & 130.73 & \multicolumn{2}{|c|}{ تحمل القوة } & \\
\hline$* 5.750$ & 1.11 & 11.50 & 1.23 & 7.45 & \multicolumn{2}{|c|}{ التصويب المتعدد للرمية الحرة } & \multirow{4}{*}{ 事 } \\
\hline *5.089 & 2.04 & 22.60 & 2.11 & 16.15 & \multirow{2}{*}{\multicolumn{2}{|c|}{ التصويب من أسفل السلة }} & \\
\hline$* 7.621$ & 1.26 & 15.71 & 1.47 & 20.25 & & & \\
\hline$* 5.162$ & 5.43 & 61.83 & 6.85 & 56.05 & \multicolumn{2}{|c|}{ المساعدة الدفاعية } & \\
\hline
\end{tabular}

قيمة "ت" الجدولية عند مستوى 0.05 ودرجات حرية 9= 2.262

يتضح من الجدول رقم (7) وجود دلالة إحصائية في جميع المتغيرات البدنية الخاصة (السرعة

الإنتقالية، تحمل القوة للرجلين والذراعين، القدرة العضلية للرجلين، القدرة على تكرار السرعة، القدرة

الهوائية، تحمل القوة) ووجود دلالة إحصائية في جميع المتغيرات المهارية الهجومية والدفاعية (التصويب المتعدد للرمية الحرة، التصويب من أسفل السلة، التحرك الدفاعي، المساعدة الدفاعية) بين القياسين القبلي والبعدي للمجموعة التجريبية حيث كانت قيمة (ت) المحسوبة أعلى من قيمة (ت) الجدولية عند

$$
\text { مستوى معنوية 0.05. }
$$

وأظهرت نتائج جدول (7) وجود فروق ذات دلالة إحصائياً للمجموعة التجريبية بين القياس القبلي والبعدي ولصالح القياس البعدي في متغير السرعة الانتقالية بعد إستخدام أسلوب التدريب المتزامن، ويعزى الباحثان تحسن السرعة الانتقالية إلى تأثير تدريبات سرعة الانطلاق، حيث يحتاج هذا النوع من السرعة إلى صفة القدرة العضلية للرجلين والمميزة للحركات الفجائية للاعبى كرة السلة، حيث أثرت تدريبات القوة والتحمل خلال البرنامج التدريبي إيجابياً في تتمية القوة المميزة بالسرعة للرجلين لدى عينة البحث التجربية، الأمر الذي تحسن معه الصفة الخاصة البدنية وهي القدرة والتي تعبر عن القوة المتفجرة الحادثة أثناء أداء انطلاقات فجائية سريعة لمسافات قصيرة، وتتفق هذه النتائج مع ما أشارت إليه دراسة سيلفيا سيدانو وآخرون Sedano, S. et al (2013م) أن التدريب المتزامن يحسن من القدرات العضلية للناشئين والمتمثلة في القدرة على تغيير الإتجاه السريع والسرعة الانتقالية. (32: 2441) 
كما يتقق مع هذه النتائج مع طلحة حسام الدين وآخرون (1997م) حيث أكد على أن التدريب باستخدام تمرينات مشابهة للأداء المهاري من حيث القوة والمسارات الحركية والعضلات العاملة يؤدى إلى تتمية السرعة الإنتقالية. (5: 136)

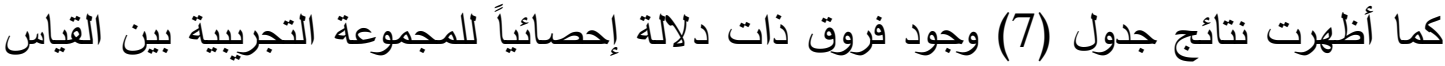
القبلي والبعدي ولصالح القياس البعدي في متغيرات القوة العضلية (تحمل القوة للرجلين والذراعين، القدرة

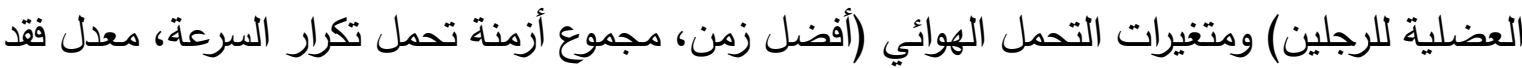

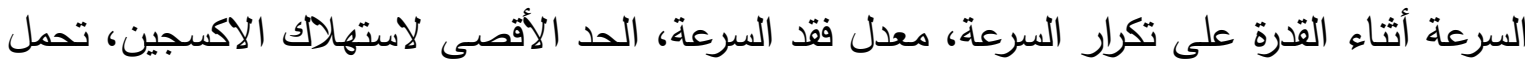
القوة)، وذلك بعد إستخدام أسلوب التدريب المتزامن للمجموعة التجريبية.

ويعزى الباحثان نتائج التحسن في متغيرات تحمل القوة العضلية للمجموعة التجريبية بعد إستخدام التدريب المتزامن إلى التحسن في مستوى المكونات البدنية الأساسية مثل القوة العضلية والمتمثلة في قدرات بدنية خاصة مثل تحمل القوة والقدرة العضلية للطرف العلوي والسفلي، حيث تميز التدريب المتزامن بتوزيع شدات التدريب باستخدام تدريبات القوة مع تدريبات التحمل في توقيت متزامن داخل الوحدة التدريبية

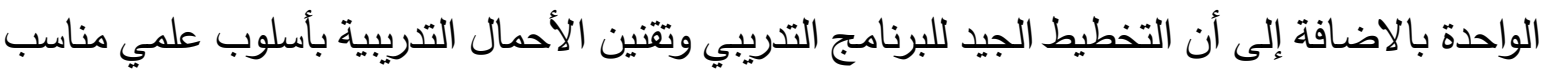

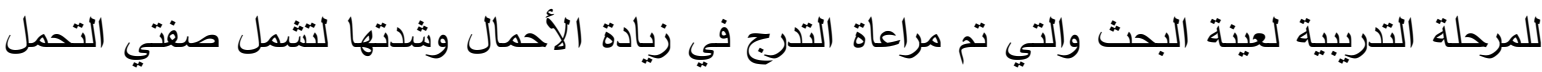

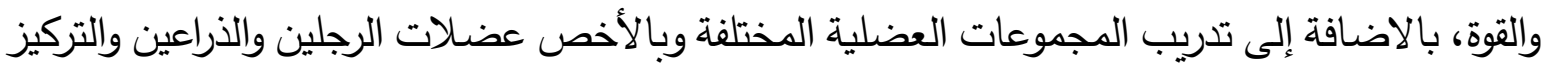

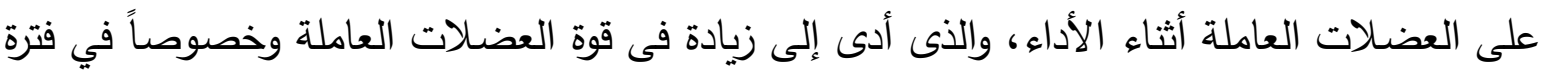

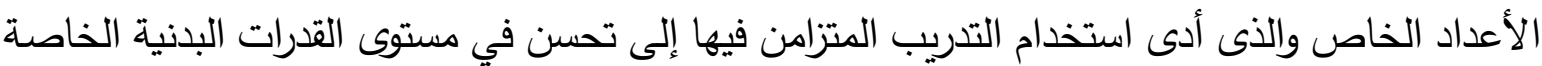
للناشئين حيث ساهم إلى حد كبير في تحسين مستوى القوة العضلية والتحمل العضلي. ويتقق ذلك مع ما أشار إليه زسولت مورلستس وآخرون Murlasits, Z. et al, (2018م)

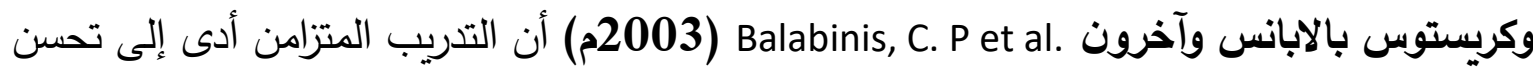
في مستوى القوة العضلية والقدرة العضلية وتحمل الأداء المهاري لدى المجموعة التجريبية. (393:9)، (24)

وأظهرت نتائج جدول (7) تحسن فى متغيرات التحمل العضلى والتحمل الهوائى للمجموعة التجريبية بعد إستخدام التدريب المتزامن والتى تمثلت في تحسن (أفضل زمن، مجموع أزمنة تحمل تكرار السرعة،

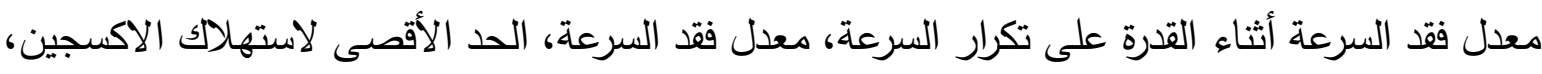

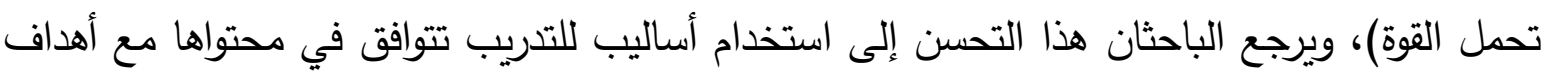
التدريب المتزامن مثل التدريب الفتري مرتفع الثدة حيث تيزامنت التدريبات المستخدمة لتتمية التحمل تزامناً مع القوة وزمن العمل أثناء الأداء كان يستهدف تتمية صفات مثل تحمل السرعة وتحمل القدرة على تكرار السرعة والحصول على راحة بينية ضئيلة، كما يعزى الباحثان التحسن في متغيرات التحمل للعينة

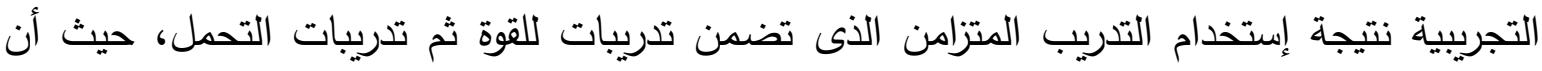


متغيرات التحمل المرتبطة بصفات القوة تعتمد على قدرة اللاعب على الأداء في غياب الأكسجين وبالتالي يحدث تكيف في زيادة حجم الألياف العضلية ونشاط الانزيمات وهذا ما أثر على تحسن القدرات البدات فئية

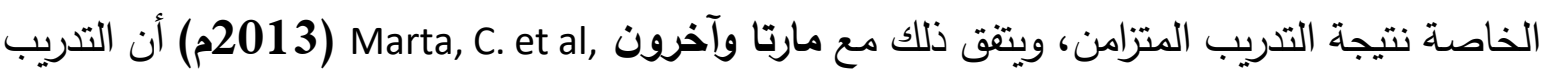

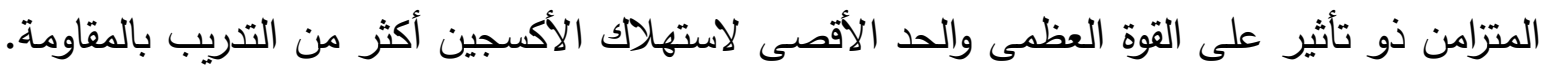

$(888: 17)$

كما يتقق ذلك مع ما أثار إليه ريسان خريبط وأبو العلا عبد الفتاح (2016م) أن العلاقة بين

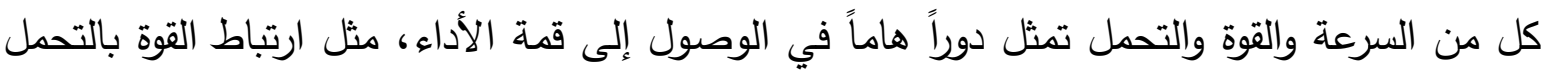

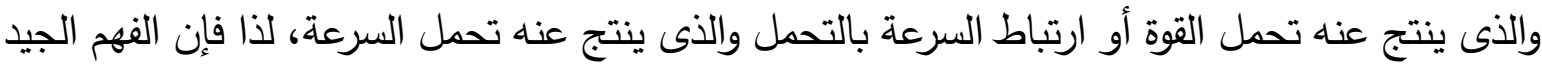

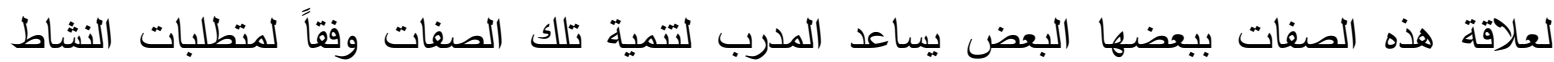
التخصصي. (4: 205 (595) كما يتضح من الجدول رقم (7) وجود دلالة إحصائية في المتغيرات المهارية (التصويب المتعدد للرمية الحرة، التصويب من أسفل السلة، التحرك الدفاعي، المساعدة الدفاعية) بين القياسين القبلي والبعدي للمجموعة التجريبية حيث كانت قيمة (ت) المحسوبة أعلى من قيمة (ت) الجدولية عند مستوى لـن معنوية 0.05. ويُعزي الباحثان وجود دلالة إحصائية في المتغيرات المهارية (التصويب المتعدد للرمية الحرة، التصويب من أسفل السلة، التحرك الدفاعي، المساعدة الدفاعية) بين القياسين القبلي والبعدي للمجموعة التحاني التجريبية إلى تطوير القدرات البدنية الخاصة بالأداء المهاري الهجومي والدفاعي في كرة السلة نتيجة لإستخدام التدريب المتزامن لعضلات الذراعان حيث ينمي عنصرى القوة والسرعة بإستخدام رد فعل

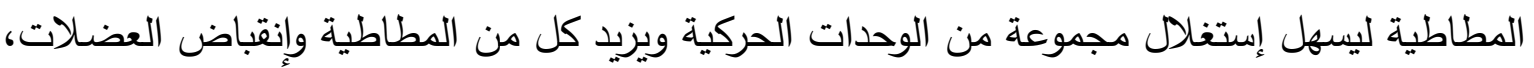
وبذلك يزيد من كفاءة العضلات للوصول إلى أقصى قوة في أقل زمن ممكن الأمر الذى إنعكس إيجابياً

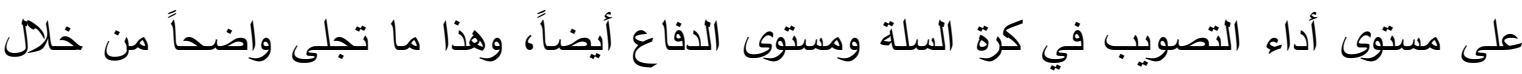

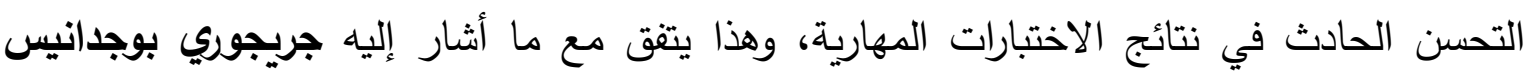
وآخرون . Bogdanis, G. C. et al (2007م) إلى فاعلية إستخدام تزامن التدريب في تحسين أداء المهارات الهجومية والدفاعية في كرة السلة. (12: 79) (200)

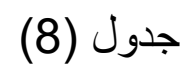

دلالة الفروق بين القياس القبلي والبعدي للمتغيرات البدنية والمهارية للمجموعة الضابطة قيد البحث ن=10 


\begin{tabular}{|c|c|c|c|c|c|c|c|}
\hline \multirow{3}{*}{ قديمة "ت" } & \multicolumn{2}{|c|}{ القياس البعدي } & \multicolumn{2}{|c|}{ القياس القبلي } & \multirow{3}{*}{\multicolumn{3}{|c|}{ المتغيرات }} \\
\hline & المتوسط & المتوسط & الانحراف & المتوسط & & & \\
\hline & الحسابى & الحسابى & المعيارى & الحسابى & & & \\
\hline 2.087 & 0.68 & 4.55 & 0.48 & 4.58 & \multicolumn{2}{|c|}{ السرعة الإنتقالية } & \\
\hline 1.157 & 4.08 & 73.20 & 4.22 & 71.73 & \multicolumn{2}{|c|}{ تحمل القوة (للرجلين) } & \\
\hline$* 2.689$ & 5.47 & 35.47 & 4.03 & 30.83 & \multicolumn{2}{|c|}{ تحمل القوة (للذراعين) } & \\
\hline 1.355 & 4.68 & 26.68 & 5.84 & 23.30 & \multicolumn{2}{|c|}{ القدرة العضلية للرجلين } & : \\
\hline 1.875 & 0.11 & 3.90 & 0.17 & 4.05 & أفضل زمن (الزمن النموذجي) & \multirow{3}{*}{ القدرة على السرعة } & \\
\hline 1.347 & 2.33 & 38.47 & 2.97 & 39.63 & مجموع الـ (12) تكرار & & $\overline{7}$ \\
\hline 1.938 & 1.14 & 7.90 & 1.30 & 8.83 & معدل فقد السرعة & & \\
\hline 2.052 & 4.47 & 44.58 & 4.68 & 45.97 & \multicolumn{2}{|c|}{ القدرة الهوائية (Vo2max) } & \\
\hline 2.010 & 10.10 & 134.73 & 9.11 & 132.40 & \multicolumn{2}{|c|}{ تحمل القوة } & \\
\hline 2.120 & 1.11 & 6.20 & 1.04 & 6.93 & \multicolumn{2}{|c|}{ التصويب المتعدد للرمية الحرة } & \multirow{4}{*}{ 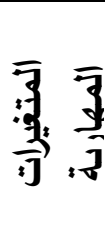 } \\
\hline 1.975 & 2.35 & 17.60 & 2.65 & 15.63 & \multicolumn{2}{|c|}{ التصويب من أسفل السلة } & \\
\hline 1.877 & 1.33 & 17.27 & 1.54 & 19.73 & \multicolumn{2}{|c|}{ التحرك الدفاعي } & \\
\hline 1.698 & 6.25 & 58.14 & 6.28 & 55.53 & \multicolumn{2}{|c|}{ المساعدة الدفاعية } & \\
\hline
\end{tabular}

قيمة "ت" الجدولية عند مستوى 0.05 ودرجات حرية 9= 2.262 يتضح من الجدول رقم (8) عدم وجود دلالة إحصائية في جميع المتغيرات البدنية الخاصة عند مستوى معنوية 0.05 ما عدا نتائج اختبار (تحمل القوة للذراعين) بين القياسين القبلي والبعدي للمجموعة الضابطة حيث كانت قيمة (ت) المحسوبة أعلى من قيمة (ت) الجدولية عند مستوى معنويـة 0.05. ويعزى الباحثان هذه النتائج الغير دالة في المتغيرات البدنية الخاصة والمرتبطة بصفة القوة العضلية والتحمل والسرعة للمجموعة الضابطة إلى أن تأثير التدريب التقليدي لم يتخطي حاجز التكيف في الأنشطة العصبية العضلية - في مدة ثمان أسابيع - والذى بمقدوره أن يعمل على تحسين صفة الإنقباضية العضلية وبالتالي يتحسن زمن العدو أو السرعة الإنتقالية أو صفات مرتبطة بالقوة العضلية، كما يعزى الباحثان عدم تطور الصفات المرتبطة بالقوة والتحمل سوياً بعد التدريب التقليدي إلى أن

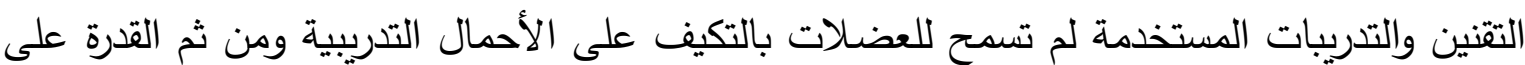
التحسن ويظهر هذه جلياً على صعيد المتغيرات الخاصة بالقوة العضلية والتحمل العضلي للرجلين Murlasits, Z. et al, والذراعين، ويتفق ذلك مع ما أشارت إليه نتائج دراسة زسولت مورلستس وآخرون (2018م) في وجود تحسن في متغيرات القوة العضلية للطرف السفلى بعد إستخدام تدريبات القوة العضلية ثم التحمل داخل الوحدة التدربية للمجموعة التجريبية مقارنة بالمجموعة الضابطة والتي لم Bell G. J. تظهر تحسناً دال في نفس المتغيرات، ويتفق ذلك أيضاً مع نتائج دراسة جي بيل وآخرون 
et al

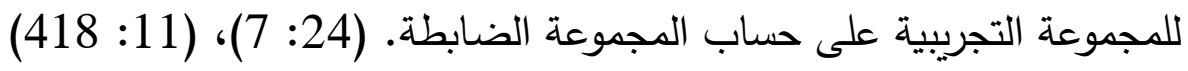
وأظهرت نتائج جدول (8) وجود فروق ذات دلالة إحصائياً بعد إستخدام التدريب التقليدي للمجموعة

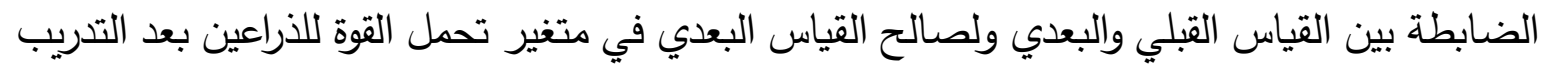
التقليدي لددة ثمان أسابيع، ويعزى الباحثان ذلك إلى أن طبيعة التدريبات المعطاة للاعبي كرة السلة

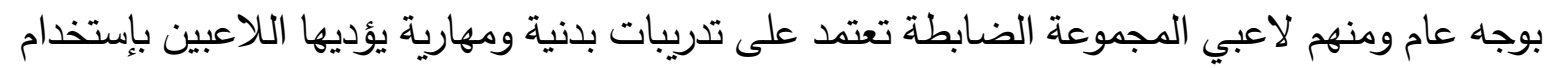

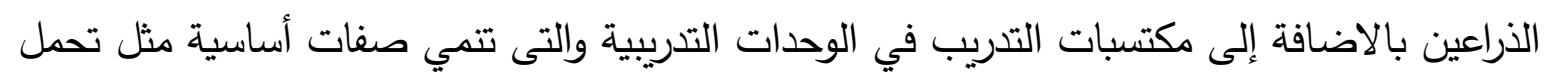

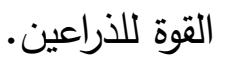

ويتضح أيضاً من جدول رقم (8) وجود دلالة إحصائية في المتغيرات المهارية الهجومية (التصويب

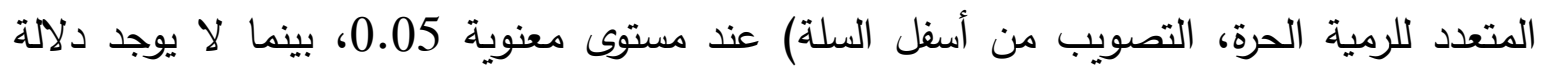
إحصائية في المتغيرات المهارية الدفاعية (التحرك الدفاعي، المساعدة الدفاعية) بين القياسين القبلي

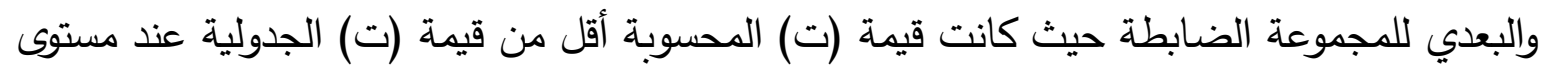
معنوية 0.05. ويُعزي الباحثان وجود دلالة إحصائية في متغير التصويب من أسفل السلة بين القياسين القبلي

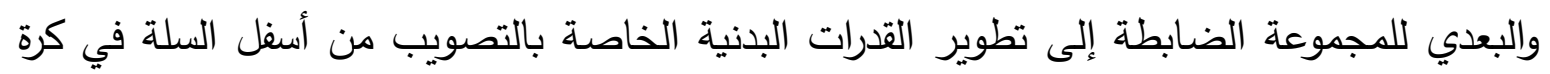
السلة نتيجة لإستخدام تدريبات عضلات الرجلين حيث ينمي عنصرى القوة والقدرة العضلية للرجلين

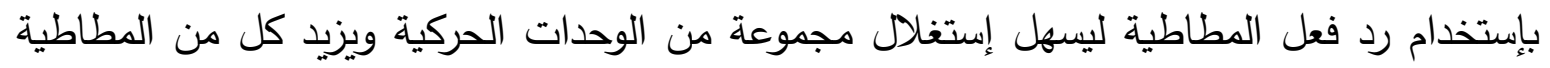

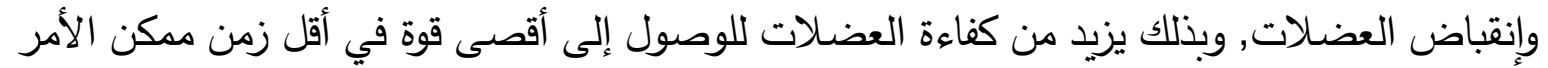

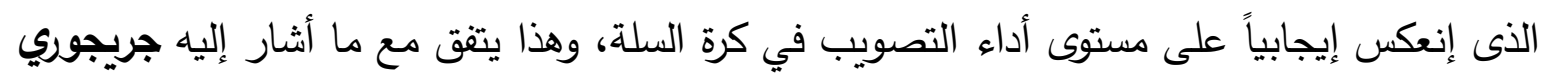

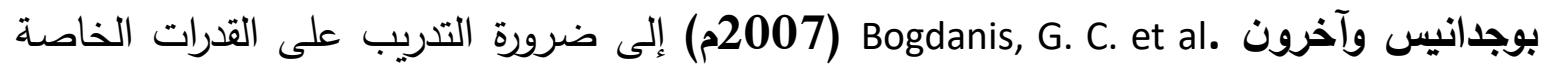

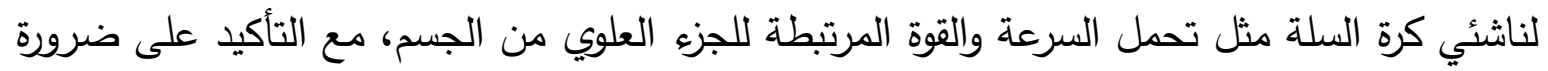
تقييم أداء الناشئين البنني والمهاري وفقاً للاختبارات البدنية والمهارية الخاصة. (12: 82 جدول (9) (9)

دلالة الفروق بين القياسين البعديين للمتغير ات البذنية و المهارية للمجمو عتين التجريبية والضابطة ن=20 


\begin{tabular}{|c|c|c|c|c|c|c|c|}
\hline \multirow{2}{*}{ قديمة "تلاتها } & \multicolumn{2}{|c|}{ المجموعة الضابطة } & \multicolumn{2}{|c|}{ المجموعة التجريبية } & \multirow{2}{*}{\multicolumn{3}{|c|}{ 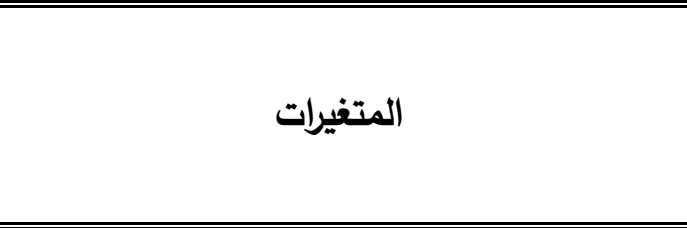 }} \\
\hline & المستوسط & الحتوسطى & الانحراف المعيارى & المتوسط الحسى & & & \\
\hline$* 4.132$ & 0.68 & 4.55 & 0.55 & 3.85 & \multicolumn{2}{|c|}{ السرعة الإنتقالية } & \\
\hline 1.931 & 4.08 & 73.20 & 3.15 & 74.76 & \multicolumn{2}{|c|}{ تحمل القوة (للرجلين) } & \\
\hline$* 5.257$ & 5.47 & 35.47 & 4.60 & 37.87 & \multicolumn{2}{|c|}{ تحمل القوة (للذراعين) } & \\
\hline$* 4.600$ & 4.68 & 26.68 & 5.40 & 29.67 & \multicolumn{2}{|c|}{ القدرة العضلية للرجلين } & : \\
\hline *3.883 & 0.11 & 3.90 & 0.21 & 3.50 & أفضل زمن (الزمن النموذجي) & \multirow{3}{*}{ القدرة على السرار } & \\
\hline$* 4.355$ & 2.33 & 38.47 & 3.81 & 35.54 & مجموع الـ (12) تكرار & & $\overline{7}$ \\
\hline$* 4.589$ & 1.14 & 7.90 & 1.60 & 5.20 & معدل فقد السرعة & & \\
\hline$* 5.833$ & 4.47 & 44.58 & 4.12 & 48.57 & \multicolumn{2}{|c|}{ القدرة الهوائية (Vo2max) } & \\
\hline 1.827 & 10.10 & 134.73 & 9.88 & 135.25 & \multicolumn{2}{|c|}{ تحمل القوة } & \\
\hline$* 6.308$ & 1.11 & 6.20 & 1.11 & 11.50 & \multicolumn{2}{|c|}{ التصويب المتعدد للرمية الحرة } & \multirow{4}{*}{ 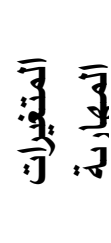 } \\
\hline$* 3.779$ & 2.35 & 17.60 & 2.04 & 22.60 & \multirow{2}{*}{\multicolumn{2}{|c|}{ التصوبب من أسفل السلة }} & \\
\hline$* 4.201$ & 1.33 & 17.27 & 1.26 & 15.71 & & & \\
\hline$* 5.681$ & 6.25 & 58.14 & 5.43 & 61.83 & \multicolumn{2}{|c|}{ المساعدة الدفاعية الداعي } & \\
\hline
\end{tabular}

قيمة "ت" الجدولية عند مستوى 0.05 ودرجات حرية 18= 2.101

يتضح من الجدول رقم (9) وجود دلالة إحصائية في جميع المتغيرات البدنية الخاصة بين التئ القياسين

البعديين للمجموعتين التجريبية والضابطة عند مستوى معنوية 0,05 ما عدا نتائج اختبار (القدرة العضلية

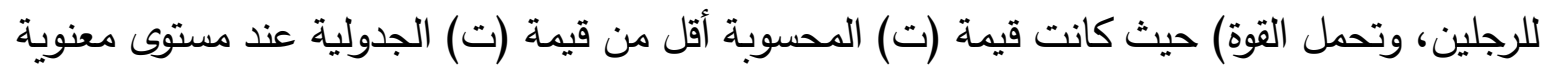

ويتضح أيضاً من الجدول رقم (9) وجود دلالة إحصائية في جميع المتغيرات المهارية الهجومية

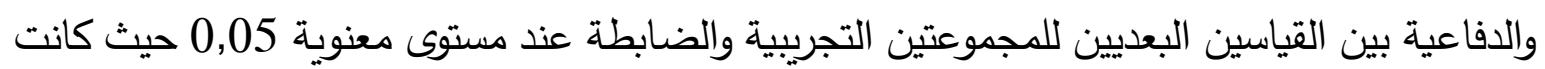
قيمة (ت) المحسوبة أعلى من قيمة (ت) الجدولية عند مستوى معنوية 0.05.

ويعزى الباحثان هذا التحسن بوجه عام في المتغيرات البنية الخاصة والمتغيرات المهارية الهجومية

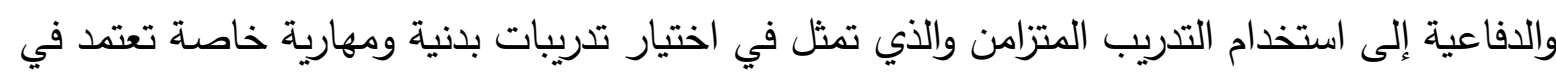

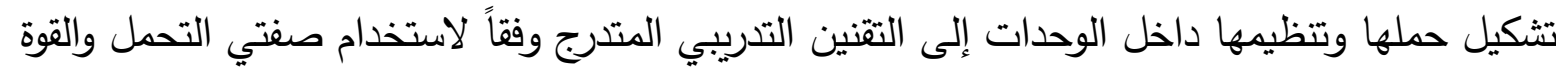

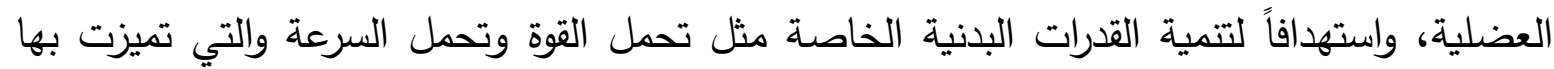

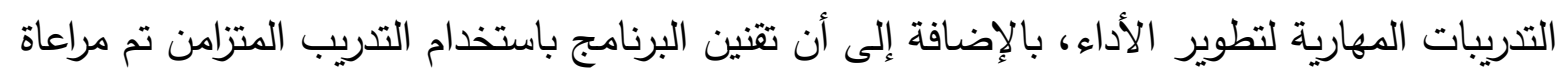

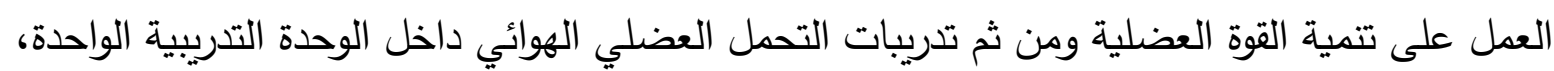

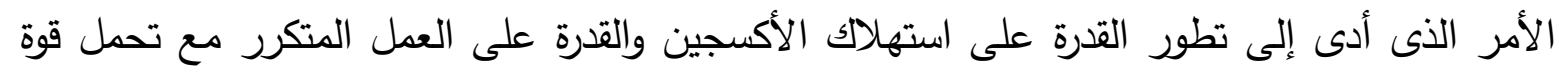

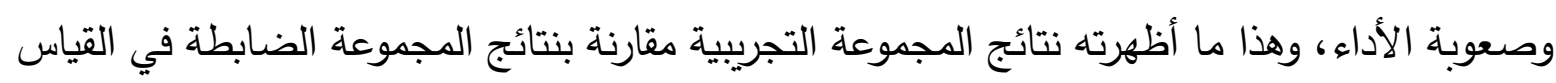


البعدي، وتتفق هذه النتائج مع ما أشار إليه زسولت مورلستس وآخرون Murlasits, Z. et al, (2018م)، وآخيان

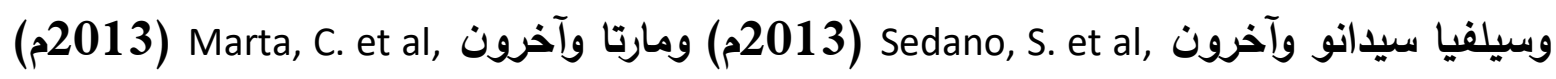
أن برنامج التدريب المتزامن أثر إيجابياً في تطوير القوة والتحمل الدوري التنفسي والقوة المميزة بالسرعة والترات

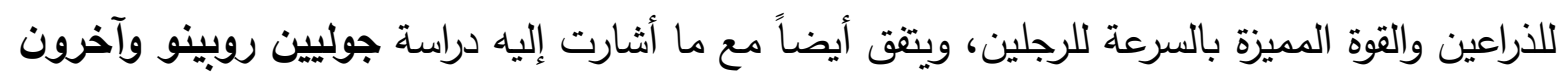
Robineau, J. et al, أسبوعياً أثر إيجابياً في تحسن متغيرات القدرة على تكرار السرعة والقدرة الهوائية ومتغيرات القدرة العضلية للجزء السفلي من الجسم، كما أكدت على أن التدريب المتزامن يحسن من القدرات العضلية العصبية لدى العى لئي الاعبين الناشئين.

(672:30)، (893:17)، (2433:32)، (6:

0/5 الإستخلاصات و التوصيات: 1/5 الإستخلاصات:

في حدود عينة البحث وخصائصها، والمنهج المستخدم، ووفقاً إلى ما أثنارت إليه نتائج التحليل

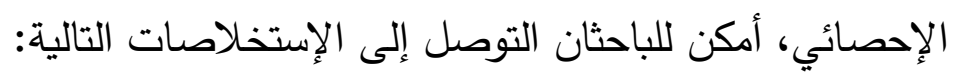

1/1/5 التدريب المتزامن لمدة ثمان أسابيع لناشئي كرة السلة أدى إلى تحسن في المتغيرات البدنية المتمثلة

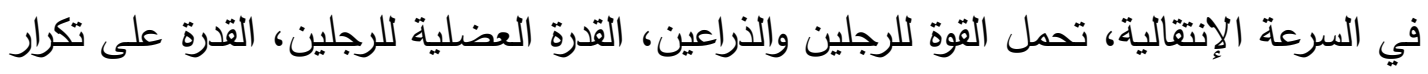
السرعة، القدرة الهوائية، تحمل القوة.

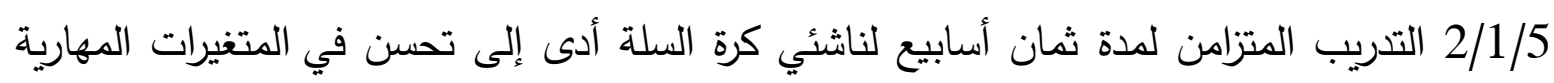

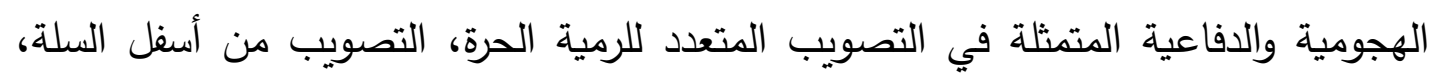
التحرك الدفاعي، المساعدة الدفاعية. 2/5 التوصيات: في ضوء النتائج والإستخلاصات التى توصل إليها الباحثان يوصى بما يلى: 1/2/5 إستخدام التدريب المقترح للتدريب المتزامن في تطوير متغيرات القوة العضلية والسرعة والتحمل والمتغيرات المهارية المرتبطة في الأنثطة الرياضية المختلفة.

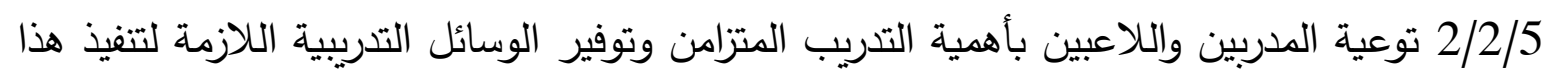
النوع من التنديب.

3/2/5 الإستعانة بالإختبارات المستخدمة في البحث وتطبيقها على عينات مختلفة وأنشطة مختلفة.

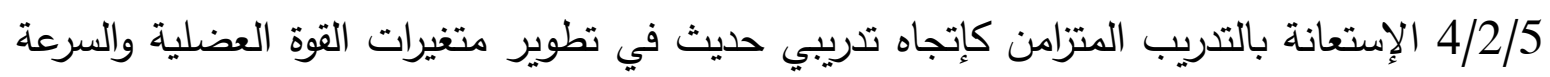
والمتغيرات المهارية المرتبطة. 0/6 قائمة المراجع: 1/6 المر اجع العربية: 
ا. عبد الأمير علوان عبود، عادل ناجي حسن، علي عاشور عبيد 2010م: وضع درجات ومستويات

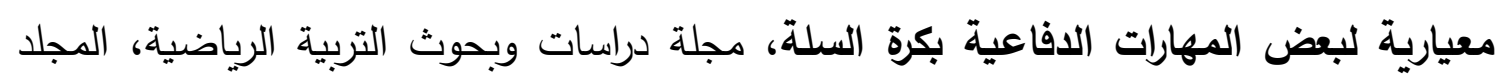
(28) - (28)، جامعة البصرة، العراق.

r. علي فهمي البيك وآخرون (2008م): سلسلة الإتجاهات الحديثة في التدربب الرياضي، الجزء الثاني، طرق قياس القدرات اللاهوائية والهوائية، منثأة المعارف، الأسكندرية.

r. علي فهمى البيك، عماد الدين عباس أبو زيد (2003م): المدرب الرياضــى فى الألعاب الجماعية

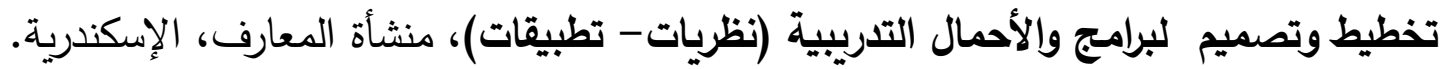

ع. ريسان خريط، أبو العلا عبد الفتاح (2016م): التدريب الرياضي، مركز الكتاب للنشر ، القاهرة.

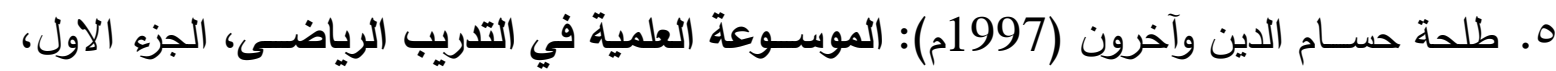
القاهرة.

T. . محمد محمود عبدالدايم، محمد صبحي حسانين (1999م): الحديث في كرة السلة - الأسس العلمية والتطبيقية، دار الفكر العربي، ط2، القاهرة.

V. مفتي إبراهيم حماد (1996م): التدريب الرياضــي للجنسـين من الطفولة إلى المراهقة، دار الفكر العربي، القاهرة.

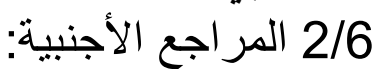

8. Aagaard, P., \& Andersen, J. L. (2010). Effects of strength training on endurance capacity in top level endurance athletes. Scandinavian journal of medicine \& science in sports, 20(s2), 39-47.

9. Balabinis, C. P., Psarakis, C. H., Moukas, M., Vassiliou, M. P., \& Behrakis, P. K. (2003). Early phase changes by concurrent endurance and strength training. Journal of Strength and Conditioning Research, 17(2), 393-401.

10. Baechle, T. R., \& Earle, R. W. (2008). National strength \& conditioning association (US). Essentials of strength training and conditioning. Champaign, IL: Human Kinetics, 395-396.

11. Bell, G. J., Syrotuik, D., Martin, T. P., Burnham, R., \& Quinney, H. A. (2000). Effect of concurrent strength and endurance training on skeletal muscle properties and hormone concentrations in humans. European journal of applied physiology, 81(5), 418-427.

12. Bogdanis, G. C., Ziagos, V., Anastasiadis, M., \& Maridaki, M. (2007). Effects of two different short-term training programs on the physical and technical abilities of adolescent basketball players. Journal of Science and Medicine in Sport, 10(2), 79-88. 
13. Brooks, G. A., Fahey, T. D., White, T. P., \& Baldwin, K. M. (2000). Cardiovascular dynamics during exercise. Exercise Physiology: Human Bioenergetics and its applications. Mountain View, Ca: Mayfield Publishing Company, 317-339.

14. Fitzsimons M., Dawson B. T., Ward D., Wilkinson A. (1993) Cycling and running tests of repeated sprint ability. Aus. J. Sci. Med. Sport. 25: 82-87

15. Franks, A., Miller, A., Bornn, L., \& Goldsberry, K. (2015). Characterizing the spatial structure of defensive skill in professional basketball. The Annals of Applied Statistics, 9(1), 94-121.

16. Goldsberry, K., \& Weiss, E. (2013). The Dwight effect: A new ensemble of interior defense analytics for the NBA. Sports Aptitude, LLC. Web, 1-11.

17. Marta, C., Marinho, D. A., Barbosa, T. M., Izquierdo, M., \& Marques, M. C. (2013). Effects of concurrent training on explosive strength and VO2max in prepubescent children. International journal of sports medicine, 34(10), 888896.

18. McCARTHY, J. P., Pozniak, M. A., \& Agre, J. C. (2002). Neuromuscular adaptations to concurrent strength and endurance training. Medicine \& Science in Sports \& Exercise, 34(3), 511-519.

19. McCormick, B. T., Hannon, J. C., Newton, M., Shultz, B., Detling, N., \& Young, W. B. (2014). A comparison of the drop step and hip turn techniques for basketball defense. International Journal of Sports Science \& Coaching, 9(4), 605-613.

20. Mackenzie, B. (2005). 101 Performance Evaluation Tests. London, Electric Word plc.

21. Meckel, Y., Gottlieb, R., \& Eliakim, A. (2009). Repeated sprint tests in young basketball players at different game stages. European journal of applied physiology, 107(3), 273.

22. Miller, D. K. (2006). Measurement by the physical educator: Why and how. New York: McGraw-Hill.

23. Mitova, O., \& Sidorenko, V. (2015). Control and analysis of dynamics of technical and tactical actions in defence during the game in basketball players of superleague team. Slobozhanskyi herald of science and sport, (3 (47), 62-64.

24. Murlasits, Z., Kneffel, Z., \& Thalib, L. (2018). The physiological effects of concurrent strength and endurance training sequence: A systematic review and meta-analysis. Journal of Sports Sciences, 1-8.

25. Murugesan, T. (2018). Impact of endurance training and concurrent strength training and detraining on cardio respiratory endurance of 
basketball players. Asian Journal of Multidimensional Research (AJMR), 7(2), 468473.

26. Nieman, D. C. (2003). Exercise testing and prescription: a health-related approach (Vol. 5). New York: McGraw-Hill.

27. Okubo, H., \& Hubbard, M. (2012). Defense for basketball field shots. Procedia Engineering, 34, 730-735.

28. Ortega, E., Palao, J. M., de Baranda, P. S., \& García, L. M. (2009). Preferences and levels of satisfaction in technical and tactical actions and in type of offense and defense utilized in competition by youth basketball players. Revista de Psicología del Deporte, 18(3), 343-348.

29. Pojskic, H., Separovic, V., Muratovic, M., \& Uzicanin, E. (2014). The relationship between physical fitness and shooting accuracy of professional basketball players. Motriæ: Revista de Educação Física, 20(4), 408417.

30. Robineau, J., Babault, N., Piscione, J., Lacome, M., \& Bigard, A. X. (2016). Specific training effects of concurrent aerobic and strength exercises depend on recovery duration. The Journal of Strength \& Conditioning Research, 30(3), 672-683.

31.Santana, F. L., Rostaiser, E., Sherzer, E., Ugrinowitsch, C., Barrera, J., \& Lamas, L. (2015). Space protection dynamics in basketball: Validation and application to the evaluation of offense-defense patterns. Motriz: Revista de Educação Física, 21(1), 34-44.

32. Sedano, S., Marín, P. J., Cuadrado, G., \& Redondo, J. C. (2013). Concurrent training in elite male runners: the influence of strength versus muscular endurance training on performance outcomes. The Journal of Strength $\&$ Conditioning Research, 27(9), 2433-2443.

33. Tanner, R., \& Gore, C. (2012). Physiological tests for elite athletes $2^{\text {nd }}$ edition. Human kinetics.

34. Tharwat Mohammed Al-Gendy, (2012). Designing New Groups of Tests for Measuring the Technical Performance of the Basketball Players. Trends in Applied Sciences Research, 7: 673-682.

35. Tie, D. I. N. G. (2006). Research of the Training Method and Present Status of the Female Amateur's Basketball Defense Ability [J]. Journal of Nanjing Institute of Physical Education (Natural Science), 2.

36. Tomkinson, G.R., Léger, L.A., Olds, T.S., \& Cazorla, G. (2003). Secular trends in the performance of children and adolescents (1980-2000): An analysis of 55 studies of the $20 \mathrm{~m}$ shuttle run in 11 countries. Sports Medicine, 33, 285-300. 
37.WANG, J. H., \& LI, Y. L. (2009). A Review and Outlook of Chinese Basketball Defensive Principles [J]. Journal of Beijing Sport University, 9.

38. Wilson, J. M., Marin, P. J., Rhea, M. R., Wilson, S. M., Loenneke, J. P., \& Anderson, J. C. (2012). Concurrent training: a meta-analysis examining interference of aerobic and resistance exercises. The Journal of Strength $\&$ Conditioning Research, 26(8), 2293-2307.

39. Wood, R. H., Reyes, R. A. F. A. E. L., Welsch, M. A., Favaloro-Sabatier, J. E. N. N. I. F. E. R., Sabatier, M. A. N. N. I. N. G., Lee, C. M., ... \& Hooper, P. F. (2001). Concurrent cardiovascular and resistance training in healthy older adults. Medicine and science in sports and exercise, 33(10), 1751-1758.

40. Yong-dong, G. U. O. (2005). Analysis on Offense and Defense Ability of the Chinese Man Basketball Team in the 28 (th) Olympic Games [J]. Journal of Beijing University of Physical Education, 4. 